\title{
Article \\ Overexpression of an Agave Phosphoenolpyruvate Carboxylase Improves Plant Growth and Stress Tolerance
}

\author{
Degao Liu ${ }^{1,2,+}$, Rongbin Hu ${ }^{1,+}{ }^{(\mathbb{D}}$, Jin Zhang ${ }^{1,2} \mathbb{D}$, Hao-Bo Guo ${ }^{3}$, Hua Cheng ${ }^{1} \mathbb{D}$, Linling Li ${ }^{1}$, \\ Anne M. Borland 1,4 (D), Hong Qin ${ }^{3}$, Jin-Gui Chen ${ }^{1,2}$, Wellington Muchero ${ }^{1,2}$, Gerald A. Tuskan ${ }^{1,2}$ (D) \\ and Xiaohan Yang $1,2, * \mathbb{D}$
}

1 Biosciences Division, Oak Ridge National Laboratory, Oak Ridge, TN 37831, USA; liudegao909@gmail.com (D.L.); rhu1@utk.edu (R.H.); zhang007jin@163.com (J.Z.); chenghua1437@126.com (H.C.); lilinling1437@126.com (L.L.); anne.borland@newcastle.ac.uk (A.M.B.); chenj@ornl.gov (J.-G.C.); mucherow@ornl.gov (W.M.); tuskanga@ornl.gov (G.A.T.)

2 The Center for Bioenergy Innovation (CBI), Oak Ridge National Laboratory, Oak Ridge, TN 37831, USA

3 Department of Computer Science and Engineering, SimCenter, University of Tennessee Chattanooga, Chattanooga, TN 37403, USA; guohaobo@gmail.com (H.-B.G.); hong-qin@utc.edu (H.Q.)

4 School of Natural and Environmental Science, Newcastle University, Newcastle upon Tyne NE1 7RU, UK

* Correspondence: yangx@ornl.gov; Tel.: +1-865-241-6895; Fax: +1-865-576-9939

+ These authors contribute equally to this work.

check for updates

Citation: Liu, D.; Hu, R.; Zhang, J.; Guo, H.-B.; Cheng, H.; Li, L.; Borland, A.M.; Qin, H.; Chen, J.-G.; Muchero, W.; et al. Overexpression of an Agave Phosphoenolpyruvate Carboxylase Improves Plant Growth and Stress Tolerance. Cells 2021, 10, 582. https://doi.org/10.3390/cells10030582

Academic Editor:

Suleyman Allakhverdiev

Received: 2 February 2021

Accepted: 18 February 2021

Published: 6 March 2021

Publisher's Note: MDPI stays neutral with regard to jurisdictional claims in published maps and institutional affiliations.

Copyright: (c) 2021 by the authors. Licensee MDPI, Basel, Switzerland. This article is an open access article distributed under the terms and conditions of the Creative Commons Attribution (CC BY) license (https:/ / creativecommons.org/licenses/by/ $4.0 /)$.

\begin{abstract}
It has been challenging to simultaneously improve photosynthesis and stress tolerance in plants. Crassulacean acid metabolism (CAM) is a $\mathrm{CO}_{2}$-concentrating mechanism that facilitates plant adaptation to water-limited environments. We hypothesized that the ectopic expression of a CAMspecific phosphoenolpyruvate carboxylase (PEPC), an enzyme that catalyzes primary $\mathrm{CO}_{2}$ fixation in CAM plants, would enhance both photosynthesis and abiotic stress tolerance. To test this hypothesis, we engineered a CAM-specific PEPC gene (named AaPEPC1) from Agave americana into tobacco. In comparison with wild-type and empty vector controls, transgenic tobacco plants constitutively expressing AaPEPC1 showed a higher photosynthetic rate and biomass production under normal conditions, along with significant carbon metabolism changes in malate accumulation, the carbon isotope ratio $\delta^{13} \mathrm{C}$, and the expression of multiple orthologs of CAM-related genes. Furthermore, AaPEPC1 overexpression enhanced proline biosynthesis, and improved salt and drought tolerance in the transgenic plants. Under salt and drought stress conditions, the dry weight of transgenic tobacco plants overexpressing AaPEPC1 was increased by up to $81.8 \%$ and $37.2 \%$, respectively, in comparison with wild-type plants. Our findings open a new door to the simultaneous improvement of photosynthesis and stress tolerance in plants.
\end{abstract}

Keywords: Agave americana; crassulacean acid metabolism; genetic engineering; Nicotiana sylvestris; phosphoenolpyruvate carboxylase; photosynthesis; drought tolerance; salt tolerance

\section{Introduction}

Human population increases, global climate changes and natural resources reductions could seriously impact food and energy security in the future [1-8]. The drylands, with precipitation amounts that are inadequate for most present-day food and bioenergy crops, covers approximately $40 \%$ of the world's land $[9,10]$. Moreover, around $20 \%$ of irrigated areas in the world are under salt stress which has become a big constraint limiting agricultural production [11-13]. In addition, the phytotoxic effects of nanoparticles could impact plant growth $[14,15]$. To address these challenges, tremendous efforts have been put into improving photosynthesis, drought tolerance and salt tolerance in crop plants through breeding and genetic engineering over the past 50 years, though there has been limited success in simultaneously enhancing both biomass production and stress tolerance [16]. One common problem shared by previous breeding and genetic engineering approaches 
is that they have focused on drought- or salt-responsive genes in $C_{3}$ or $C_{4}$ species, with narrow genetic diversity for the tolerance of abiotic stresses.

A potential solution to this problem can be obtained from the desert plants that employ crassulacean acid metabolism (CAM) for photosynthesis (e.g., Agave americana), as these plants maximize water-use efficiency (WUE) by shifting all or part of their net atmospheric carbon dioxide $\left(\mathrm{CO}_{2}\right)$ uptake to the nighttime, when the evapotranspiration rates are generally lower than that in the daytime $[1,2,8,9,17]$. The nocturnal $\mathrm{CO}_{2}$ taken up in CAM plants is intracellularly fixed, usually leading to the generation of $\mathrm{C}_{4}$ organic acid (e.g., malate) as storage intermediates, which accumulate in the vacuole during the dark period before being gradually catabolized during the day [2,9]. High rates of malate decarboxylation behind closed stomata during the day can concentrate $\mathrm{CO}_{2}$ from 2- to 60-fold around ribulose-1-5-bisphosphate carboxylase/oxygenase (Rubisco) [9,18]. This effectively creates a ' $\mathrm{CO}_{2}$ pump' that can strongly favor the carboxylase activity of Rubisco and potentially suppress photorespiration, a process that can reduce photosynthesis by up to $40 \%$ in $C_{3}$ photosynthesis plants $[1,2,9,19-21]$. In addition, as an obligate CAM species, Agave americana is highly tolerant to salinity with an electrical conductivity (EC) level of $9.4 \mathrm{dS} \mathrm{m}^{-1}$ [22]. Additionally, A. americana has been reported to achieve high biomass productivity and drought tolerance when grown as a crop on arid and semi-arid lands [23].

CAM photosynthesis can be divided into nocturnal and day-time reactions [24-27]: At night atmospheric $\mathrm{CO}_{2}$ is taken up through open stomata and primary fixation of $\mathrm{CO}_{2}$ (as $\mathrm{HCO}_{3}{ }^{-}$) by phosphoenolpyruvate carboxylase (PEPC) produces oxaloacetate (OAA) that is subsequently converted to malate by malate dehydrogenase (MDH). Malate is transported by tonoplast-localized aluminum-activated malate transporter (ALMT) into the vacuole, where it is stored as malic acid throughout the dark period. During the light period, Rubisco fixes the $\mathrm{CO}_{2}$ released from NAD(P)-malic enzyme (ME)- or PEP carboxykinase (PEPCK)-mediated malate decarboxylation when stomata are closed $[9,19]$. It has been shown that PEPC is a highly abundant enzyme in leaves of $A$. americana and its transcript level and protein abundance are correlated with CAM [28]. In this study, we identified a CAM-isoform PEPC through genome-wide analysis of the PEPC gene family in A. americana, as well as protein structure modeling analysis and molecular dynamics (MD) simulation studies. We then determined the impacts of the overexpression of the Agave $P E P C$ on the photosynthetic carbon metabolism, and abiotic stress tolerance in the model $\mathrm{C}_{3}$ plant tobacco.

\section{Materials and Methods}

\subsection{Genome-Wide Analysis of the PEPC Gene Family}

Arabidopsis thaliana PEPC sequences (AT1G68750.1, AT1G53310.1, AT3G14940.1, and AT2G42600.2) were retrieved and used as queries in BLAST searches against Agave americana transcriptomics data [28] to identify potential PEPC genes. An expectation (E) value of $<1 \times 10^{-10}$ was used to obtain the homologous protein sequences of the predicted PEPC family members. The expression data of the Agave PEPCs were also obtained from the A. americana transcriptomics data [28]. For gene expression patterns of Agave PEPC, the $\log 10$ transformed FPKM values and z-score normalized relative expression were used for heatmap analysis.

\subsection{Phylogenetic Analysis}

Multiple alignment of PEPC proteins was performed using the MAFFT online service [29]. The maximum likelihood (ML) phylogenetic tree was constructed using W-IQTREE [30]. The sequences used for the analysis were: foxtail millet (AY491400), foxtail millet $\mathrm{C}_{4}$ (AF495586), maize $\mathrm{C}_{3}$ (X61489), maize $\mathrm{C}_{4}$ (X15642), maize root (AB012228), rice $\mathrm{C}_{3}$ (Os08g0366000, Os09g0315700, and Os01g0758300), rice root (Os02g0244700), sorghum $\mathrm{C}_{4}$ (X63756), sugarcane $C_{3}$ (M86661), sugarcane $C_{4}$ (AY135709), and wheat (AJ007705) [31]. The bootstrap values were calculated as percentages for 1000 replications. 


\subsection{Structural Modeling and Molecular Dynamics Simulation}

The A. americana PEPC model was constructed using the I-TASSER v. 5.1 protein structure modeling toolkit [32]. Structure averaging from multiple MD simulations or a single long time-scale MD simulation could effectively refine the predicted structures [33]. Here, starting with the best I-TASSER model, the rotamer states of Asn, Gln, and His residues as well as protonation states of titratable residues were validated by MolProbity [34]. The HBUILD module in CHARMM [35] was employed to add missing hydrogen atoms to the model. A water box with the size of $118 \times 106 \times 102 \AA 3$ (at least $15 \AA$ to the edge of the protein) was used, and sodium and chloride ions were added to neutralize the net charge. The final model contained 120,210 atoms with 34,893 water molecules. NAMD [36] was used to perform the MD simulations with the CHARMM protein force field [37] and TIP3P water model [38]. Using the SHAKE algorithm to fix all bond lengths involving hydrogen atoms, a time step of 2-fs was applied to all MD simulations. A 50k-step energy minimization was conducted, followed by a "natural" heating to $300 \mathrm{~K}$ with the rate of $0.001 \mathrm{~K} / \mathrm{step}$ for $300 \mathrm{k}$ steps. An NPT ensemble maintained by Langevin piston controls was used in the MD simulations with a system pressure of $1 \mathrm{~atm}$ and a temperature of $300 \mathrm{~K}$. A cutoff switching between 9 and $11 \AA$ was applied for non-bonded interactions. The particle mesh Ewald (PME) summation was applied for long-range electrostatic interactions with a grid spacing of $1.35 \AA$. MD simulation was performed for $200 \mathrm{~ns}$, and analysis was carried out on the final $50 \mathrm{~ns}$ of the MD trajectory. The PDBsum online tool [39] was used to plot the cartoon topology of the protein structure.

\subsection{Plasmid Construction}

A 2943-bp DNA fragment containing the coding sequence of AaPEPC1 (Aam080248) [28] fused to two FLAG epitope tags [40] was chemically synthesized by Integrated DNA Technology (Coralville, IA, USA) and used to produce a chimeric gene construct, p35S:FLAG$A a P E P C 1 /$ pNOS: nptII. The vector contains the CaMV35S promoter which drives FLAG$A a P E P C 1$, and the nopaline synthase (NOS) promoter which drives the nptII gene for kanamycin resistance as a selection marker. The vector was delivered into the GV3101 Agrobacterium tumefaciens strain via the freeze-thaw method [41] for plant transformation.

\subsection{Plant Transformation}

A tobacco (Nicotiana sylvestris) cultivar (USNGC TW136, PI555569) was used for genetic transformation. The generation and culturing of transgenic plants were carried out as previously described [42]. The transgenic lines were based on single copy lines with a segregation ratio of approximately 3:1 (kanamycin resistance vs. sensitivity) in the T1 generation, and homozygous lines were presumed if there was no segregation in the T2 and T3 generations $(n>100)$.

\subsection{Measurement of Photosynthesis}

The photosynthetic rates of leaves of transgenic and wild-type (WT) plants that were well-watered and grown in pots for 6 weeks was measured as previously described [11]. Mature leaves from 3 individual replicate plants were used for gas exchange analysis by an LI-COR Portable Photosynthesis System (LI-COR Inc., Lincoln, NE, USA). The relative chlorophyll content (SPAD value in fresh leaves) was analyzed using an SPAD-502 Chlorophyll Meter (Minolta, Japan) [11].

\subsection{Analysis of Malate, Glucose and Proline Content}

Mature leaves were sampled and frozen in liquid nitrogen at the indicated times and stored at $-80^{\circ} \mathrm{C}$ until use. The leaf samples were ground to a fine powder and assayed for malate and glucose content using the standard enzyme-linked spectrophotometric methods according to the manufacturer's instructions (Sigma-Aldrich, St. Louis, MO, USA), respectively.

The proline content was measured as described by He, et al. [43]. 


\subsection{Carbon Isotope Ratio Analysis}

Plants were well watered throughout the growing period. Mature leaves were harvested from 6-week-old plants and dried for 1 week at $50^{\circ} \mathrm{C}$. Finely ground dry powder was placed in capsules and then analyzed at the University of California Davis Stable Isotope Facility (http:/ / stableisotopefacility.ucdavis.edu, accessed on 25 February).

\subsection{Salt and Drought Stress Treatment}

For salt tolerance analysis, the transgenic plants and controls were watered with $200 \mathrm{mM} \mathrm{NaCl}$ solution every other day for 4 weeks as previously described [11]. For drought tolerance analysis, the transgenic and WT plants were exposed to progressive drought stress by withholding water until a nearly lethal effect of dehydration was observed on the WT. A recovery study was carried out for plants under drought stress by re-irrigating with water [44]. After salt or drought treatment, all plants were dried for $48 \mathrm{~h}$ in an oven at $80^{\circ} \mathrm{C}$ and weighed [11]. All treatments were performed in triplicate.

\subsection{Expression Levels Analysis of the Related Genes}

The expression levels of related genes in the transgenic and WT plants were analyzed by qRT-PCR as previously described [11]. Total leaf RNA was extracted from transgenic and WT plants using the Spectrum Plant Total RNA Kit (Sigma-Aldrich, St. Louis, MO, USA). RNA samples were reverse-transcribed using a High-Capacity cDNA Reverse Transcription Kit (Applied Biosystems, Foster City, CA, USA). The cDNA solution was used as a template for qPCR amplification using SYBR Green Master Mix (Applied Biosystems, Foster City, CA, USA) with the specific primers designed for each gene (Supplementary Table S1). The tobacco actin gene was used as an internal control (Supplementary Table S1). The quantification of the gene expression level was performed with comparative CT method [45].

\subsection{Statistical Analysis}

The data presented as the mean \pm SD were analyzed by a one-way ANOVA analysis with post-hoc Tukey honestly significant difference (HSD) test. $p$-values of $<0.05$ or $<0.01$ were considered to be statistically significant.

\section{Results}

\subsection{CAM-Specific PEPC in Agave americana}

Through a tBLASTn search against $A$. americana transcriptomics data [28], using the PEPC protein sequences of Arabidopsis thaliana as queries, we identified a total of 21 transcripts encoding PEPC in A. americana. Several types of PEPC are present in plants, including plant-type PEPCs (PTPCs) and one bacterial-type PEPC (BTPC) [46,47]. The plant-type PEPCs studied so far have been classified into four groups: $\mathrm{C}_{3}, \mathrm{C}_{4}$, and CAMtypes from photosynthetic tissues and root-type from non-photosynthetic tissue [31]. In order to gain insight into the evolutionary relationships among PTPCs, we constructed a phylogenetic tree using the 21 predicted Agave PEPC transcripts and the $\mathrm{C}_{3^{-}}, \mathrm{C}_{4^{-}}, \mathrm{CAM}-$ and root-type PEPCs from rice (Oryza sativa), maize (Zea mays), wheat (Triticum aestivum), sugarcane (Saccharum spp.), sorghum (Sorghum bicolor), foxtail millet (Setaria italica) and orchid (Phalaenopsis equestris) [24,31]. A phylogenetic analysis of the plant-type PEPCs indicated that Aam080248 [28] (named AaPEPC1) belongs to CAM-type PEPC (Figure 1a). Our results also showed the CAM- and $\mathrm{C}_{4}$-type PEPCs belong to different clades, suggesting that these two PEPC types evolved independently. 
a
$\mathrm{C}_{3}$ type
Root type
- $\mathrm{C}_{4}$ type
CAM type

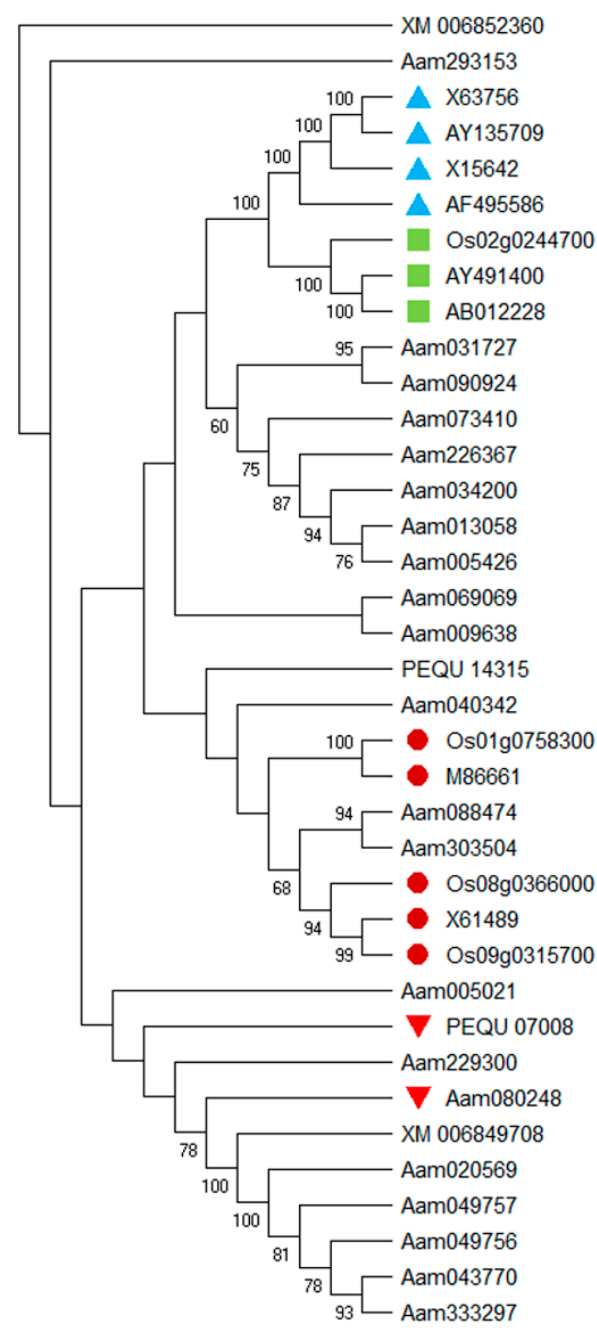

b
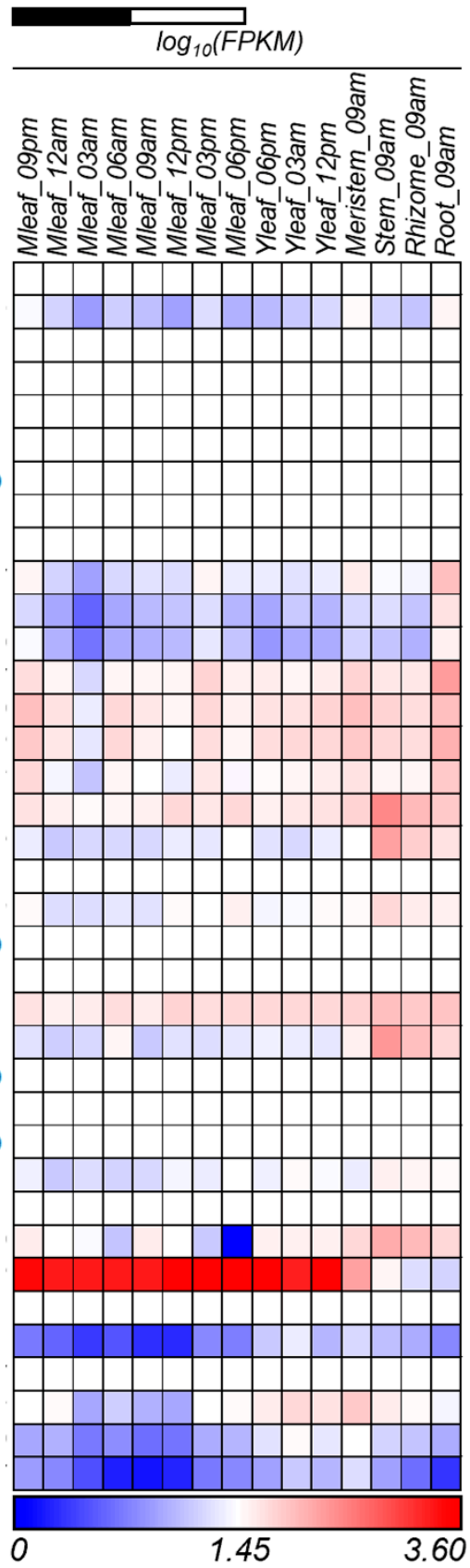

Relative expression (Z-score)

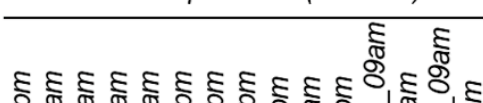

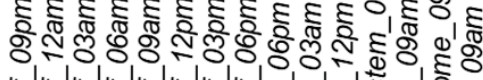

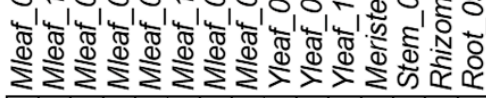
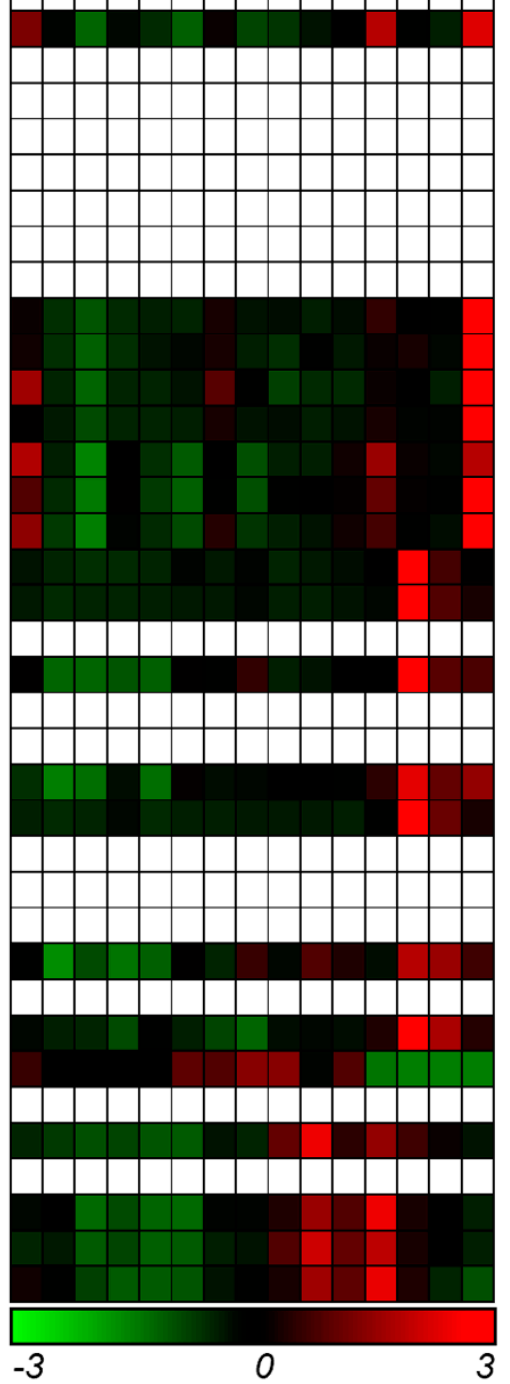

Figure 1. Identification of the crassulacean acid metabolism (CAM)-isoform of phosphoenolpyruvate carboxylases (PEPC) in Agave americana. (a) Phylogenetic relationships of PEPCs in A. americana and plant-type PEPCs from other monocot plants. Bootstrap values are shown at nodes. The sources for the PEPC sequences (as well as species abbreviations, etc.) are provided in 'Materials and Methods'. (b) Diel transcript expression of the PEPC genes in A. americana. The Z-score is defined as $\left(x_{i}-\mu_{i}\right) / \sigma_{i}$, where $x_{i}$ is the FPKM of gene $i, \mu_{i}$ is the mean and $\sigma_{i}$ is the standard deviation of all 15 columns. White and black bars indicate daytime $(12 \mathrm{~h})$ and nighttime $(12 \mathrm{~h})$, respectively. Mleaf: mature leaf; Yleaf: young leaf.

Using the quantitative gene transcript abundance data obtained from the transcriptome analysis of 15 tissues, including mature leaves sampled over a diel cycle (eight time-points) and, young leaves (three time-points), meristem, stem, root and rhizome in A. americana [28], we obtained the transcript pattern of the 21 PEPC transcripts (Figure 1b), Among which Aam080248 was the most abundant transcript in mature leaves, with a transcript abundance peak during the late afternoon just before the start of the dark period. 
These results supported the above computational phylogenetic prediction (Figure 1a) that the Aam080248 gene encodes the CAM-specific PEPC in A. americana.

\subsection{AaPEPC1 Binds to Phosphoenolpyruvate}

Phosphoenolpyruvate (PEP) is the substrate for PEPC enzymes [48,49]. To understand whether AaPEPC1 binds to PEP, we developed a protein structural model using I-TASSER (v.5.1) accompanied by a $200 \mathrm{~ns}$ MD simulation (Figure 2a-c). The last 50 ns of the MD trajectory were taken to refine the AaPEPC1 structure. The root mean square deviation (RMSD) of the $\alpha$-carbon atoms of all residues was approximately $2.0 \AA$ (Figure 2c), which is reasonable for fluctuations of the 964 amino acids (AA) protein. From the last $50 \mathrm{~ns}$ MD trajectory, the snapshot that was closest to the average structure (with RMSD $=0.8 \AA$ ) was selected as the final model (Figure 2a,b). Since the crystal structures of bacterial (Escherichia coli) PEPC (PDB entry 1JQN) and Z. mays $\mathrm{C}_{4}$-type PEPC (PDB entry 5VYJ) are well-characterized [48-50], we compared the protein structure of AaPEPC1 with the E. coli PEPC and Z. mays $\mathrm{C}_{4}$-type PEPC. In line with E. coli PEPC and Z. mays $\mathrm{C}_{4}$-type PEPC, the AaPEPC1 model was found to be dominated by $\alpha$-helix regions (546 AAs, $57.7 \%$ ). The Ramachandran plot of the AaPEPC1 structure was found to have $93.4 \%$ (804 AAs) in the most favorable regions, compared to $92.6 \%$ for the E. coli PEPC and $90.5 \%$ for the Z. mays $\mathrm{C}_{4}$-type PEPC (Figure 2d-f). In addition, 5.2\% (45 AAs) of AaPEPC1 were found to be in the additional allowed regions (7.1\% for E. coli PEPC and $8.7 \%$ for Z. mays $\mathrm{C}_{4}$-type PEPC), $1.2 \%$ (10 AAs) were found to be in the generously allowed regions $(0.1 \%$ for E. coli PEPC and $0.2 \%$ for $Z$. mays $\mathrm{C}_{4}$-type PEPC) and $0.2 \%$ (2 AAs) were found to be in disallowed regions $\left(0.1 \%\right.$ for E. coli PEPC and $0.3 \%$ for $Z$. mays $C_{4}$-type PEPC). The $\mathrm{N}$-terminus of AaPEPC1 was found to contain the plant-specific serine residue (S9) (Figure 2a), which is located in the middle of an $\alpha$-helix flanked by a long loop region. The plant-specific Ser residue near the $\mathrm{N}$-terminus of PEPC is well-known in $\mathrm{C}_{4}$ plant species $[48,51]$. This serine residue, however, was absent in bacterial PEPC (e.g., E. coli PEPC, PDB entry 1JQN) (Figure 2a,b). The AaPEPC1 model suggested that the AaPEPC1 can efficiently bind to PEP, which is bound by H171 and R640, where R640 is located at a GRGXXGR ${ }^{640}$ GG motif (Figure 2a) and is overlapped with R647 in the Z. mays $\mathrm{C}_{4}$-type PEPC, whereas H171 is overlapped with H177 in the Z. mays $\mathrm{C}_{4}$-type PEPC, hence both H171 and R640 in AaPEPC1 may directly participate in the carboxylation reaction as proposed in the $\mathrm{C}_{4}$-type PEPC [48]. In addition, based on the PEP-AaPEPC1 complex model, R449 (R456 in Z. mays $\mathrm{C}_{4}$-type PEPC) may also be involved in PEP binding and PEPC catalysis. 


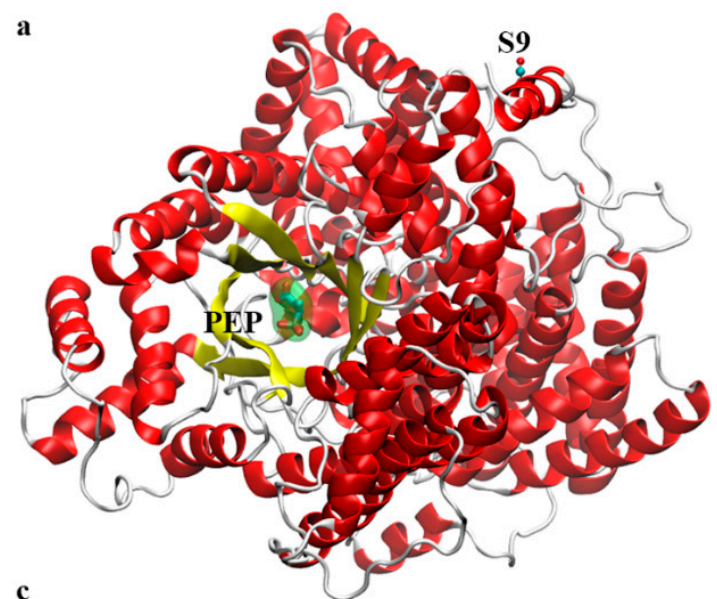

b

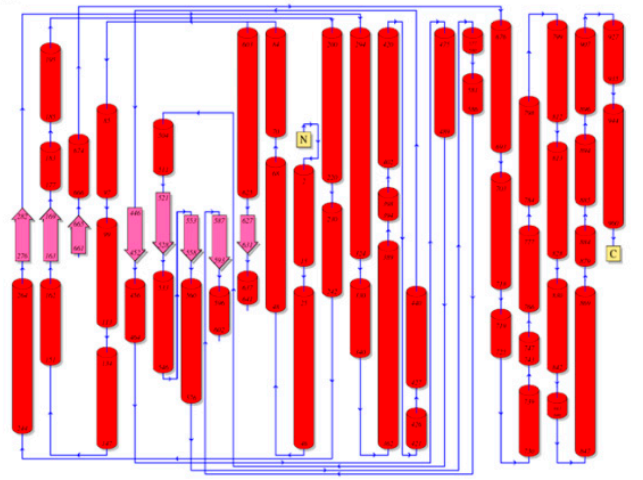

RMSD of $\mathrm{C}_{\alpha}$ atoms from the last $50 \mathrm{~ns}$

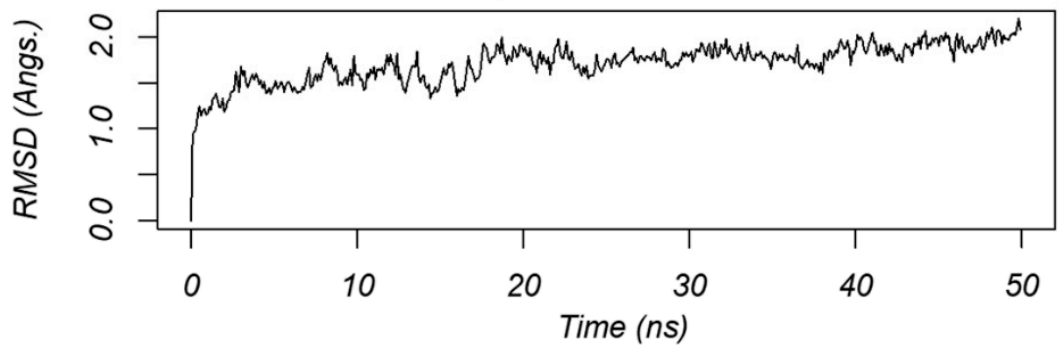

d

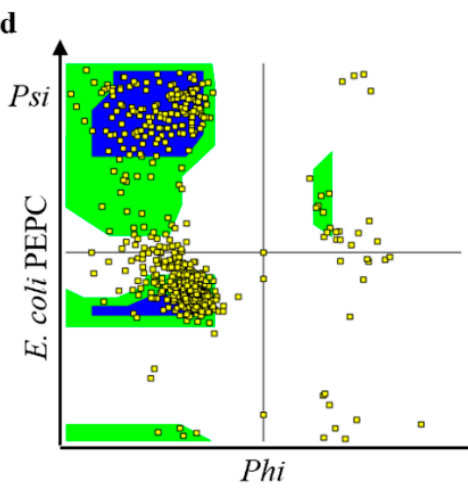

f
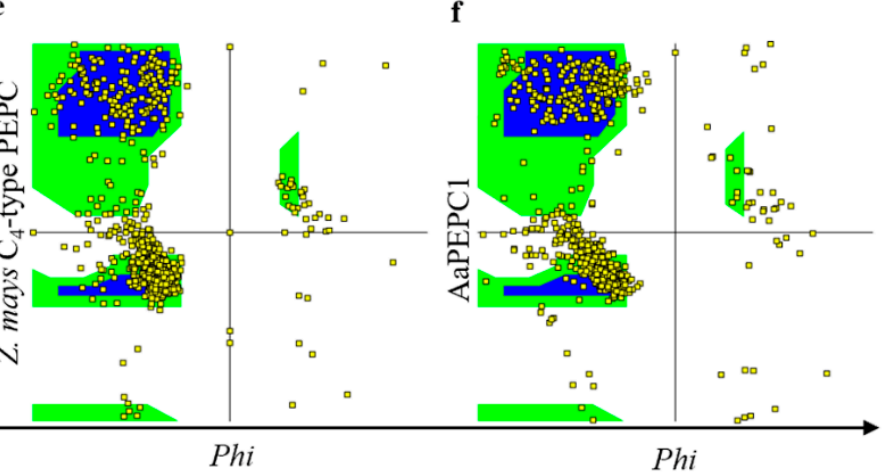

Figure 2. AaPEPC1 binds to phosphoenolpyruvate (PEP) substrate. (a) Left: AaPEPC1 structure selected from $200 \mathrm{~ns}$ molecular dynamics (MD) simulation that is closest to the average structure of the whole trajectory (root mean square deviation $\mathrm{RMSD}=0.8 \AA$ ). The protein structure is shown in cartoons with helices in red, strands in yellow and coils/turns in white. A PEP substrate that binds to the $\beta$-barrel (yellow) active site is shown in sticks and spheres. The plant-specific $\mathrm{N}$-terminal serine residue (S9) is also shown. The binding position of the PEP substrate was obtained from the Escherichia coli PEPC-PEP complex (PDB entry 1JQN) [50]. (b) A cartoon representation of the topology of AaPEPC1 structure. The cylinders represent alpha-helices. (c) The RMSD (A) profile of the final 50 ns of the MD simulation. The deviations of all snapshots to the average MD structure are $1.4 \pm 0.2 \AA$ (not shown). (d-f) Ramachandran plot of the E. coli (PDB entry 1JQN) PEPC, Zea mays $\mathrm{C}_{4}$-type PEPC (PDB entry 5VYJ) [49], and AaPEPC1 (the final snapshot of the $200 \mathrm{~ns}$ MD trajectory), respectively.

\subsection{Development of Transgenic Tobacco Lines Overexpressing AaPEPC1}

After we identified the CAM-isoform of PEPC from A. americana, we wanted to determine the impact of overexpressing this Agave gene on the photosynthetic carbon metabolism and abiotic stress tolerance in Nicotiana sylvestris (tobacco), which is a $C_{3}$ plant species. The AaPEPC1 coding sequence was cloned into binary vector pBI121, downstream of the cauliflower mosaic virus 35S (CaMV35S) promoter, to yield p35S::AaPEPC1 for transformation into N. sylvestris (Supplementary Figure S1a). The p35S::AaPEPC1 vector and empty vector (pBI121) were transferred into tobacco via $A$. tumefaciens-mediated genetic 
transformation [42]. Transformants harboring a single copy of transgene were identified from the segregation ratio for kanamycin resistance. Two T2 transgenic homozygous lines (p35S::AaPEPC1_OE1 and p35S::AaPEPC1_OE2) exhibiting different expression levels of the AaPEPC1 (Supplementary Figure S1b) were selected as representative lines for subsequent phenotypic characterization.

\subsection{Overexpression of AaPEPC1 Increases Photosynthetic Rate and Changes Stable Carbon Isotope Ratio}

We determined whether the constitutive overexpression of AaPEPC1 affected or influenced the photosynthetic rate in the transgenic tobacco plants, along with empty vector (EV) and WT control plants, grown under normal conditions (12 h light/12 h dark photoperiod; without drought- or salt-stress) at four time points (i.e., 3, 9, 15 and $21 \mathrm{~h}$ after the beginning of the light period). The transgenic plants overexpressing AaPEPC1 showed significantly higher photosynthetic rates than the WT and EV controls in the light period (Figure 3a). A carbon isotope ratio $\delta^{13} \mathrm{C}$ is a broadly accepted indicator of the extent to which the biomass is derived from PEPC-mediated $\mathrm{CO}_{2}$ fixation in plants, because PEPC discriminates less against ${ }^{13} \mathrm{C}$ than Rubisco which is responsible for most $\mathrm{CO}_{2}$ fixation in $\mathrm{C}_{3}$ plants during the light period [52]. The positive correlation between the $\delta^{13} \mathrm{C}$ values and CAM activity has been demonstrated to be a simple and reliable method for determining the type of photosynthesis, including that of $C_{3}, C_{3}-C A M$ intermediate and CAM [52-54]. In this study, we found that the $\delta^{13} \mathrm{C}$ values were significantly increased (i.e., became less negative) in the transgenic line (OE2), in which the expression level of AaPEPC1 was 7.74-fold higher than that in the other transgenic line (OE1) (Supplementary Figure 1b), in comparison with the controls (Figure $3 b$ ), thus indicating that this transgenic line was using PEPC for photosynthetic carbon assimilation and production of biomass.

\subsection{The Impact of AaPEPC1 Overexpression on the Accumulation of Malate and Glucose}

PEPC functions in the production of OAA, thus leading to synthesis of malate/malic acid, which is a key intermediate of the tricarboxylic acid (TCA) cycle that links lipids and glucose metabolisms with photosynthesis in $C_{3}$ plants $[47,55]$. The diel fluctuation in malate content represents a central biochemical correlate of the CAM photosynthesis pathway [9]. Additionally, the glycolytic breakdown of glucose provides substrate for the primary carboxylation reaction at night whilst the day-time recovery of glucose via gluconeogenesis is an important sink for $C$ released from malate decarboxylation $[9,56]$. To determine the impact of AaPEPC1 overexpression on malate and glucose production in transgenic tobacco, the malate and glucose contents were measured at four time points (i.e., 3, 9, 15 and $21 \mathrm{~h}$ after the beginning of the light period). The transgenic plants overexpressing AaPEPC1 showed higher malate and glucose contents than the WT and EV controls at all four time points during the day and night (Figure 3c,d). Furthermore, the transgenic plants expressing AaPEPC1 showed a significant increase in malate content at $15 \mathrm{~h}$ compared to that at $9 \mathrm{~h}$ after the beginning of the light period, while no significant difference was found between the malate contents at 15 and $9 \mathrm{~h}$ in the control plants (Figure 3c). The rewired diel malate accumulation-depletion pattern suggested that AaPEPC1 overexpression affects primary carboxylation in transgenic plants. Additionally, we found that higher amounts of glucose were broken down in the early night (at $15 \mathrm{~h}$ after the beginning of the dark period) in the transgenic plants overexpressing AaPEPC1 compared with control plants (Figure 3d), suggesting that the overexpression of the AaPEPC1 enhances glycolysis and consequently supplies more substrates for primary carboxylation. 
a

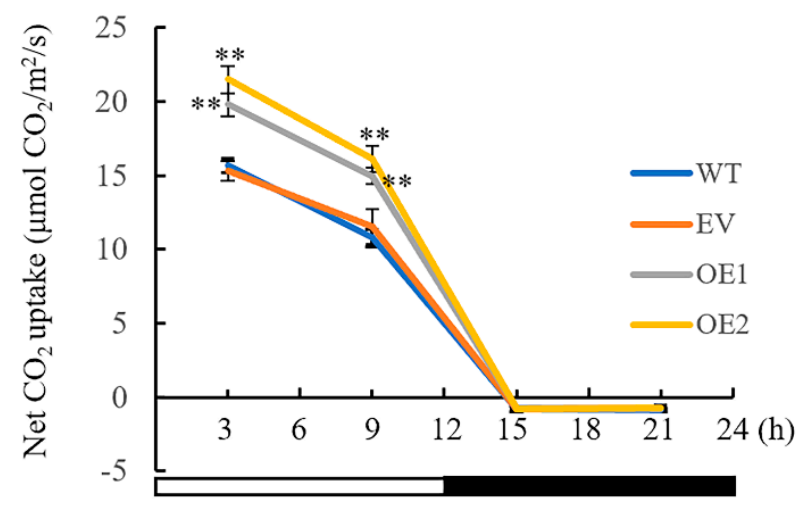

C

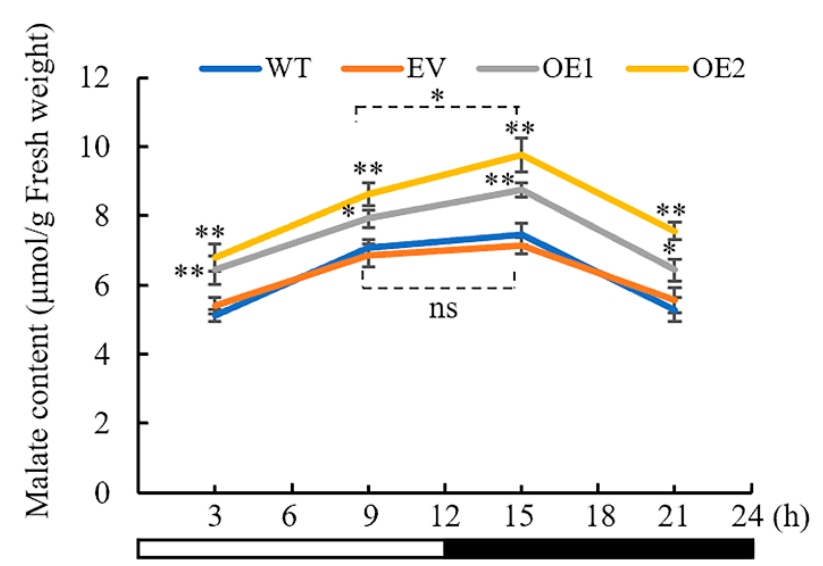

b

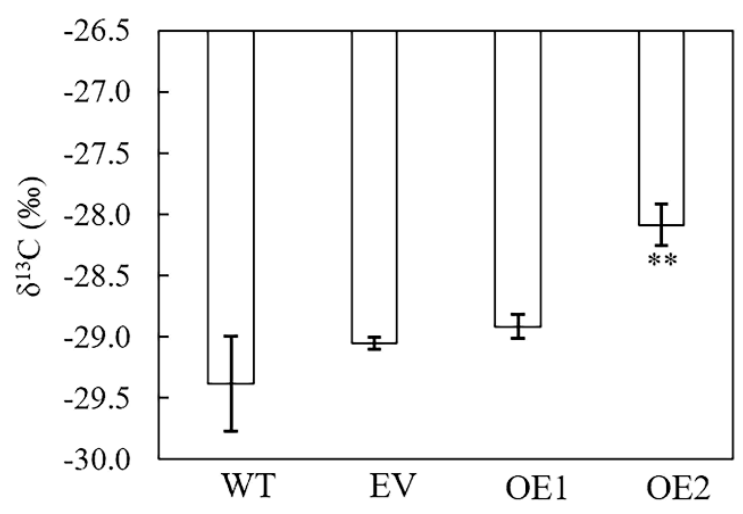

d

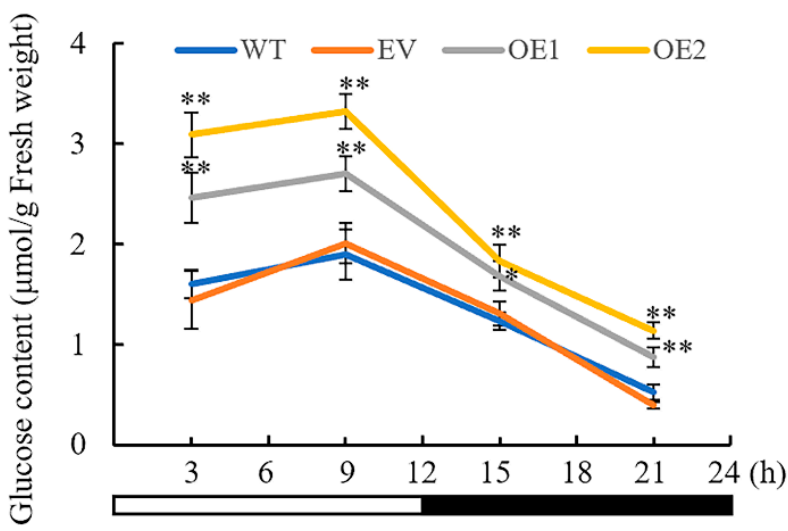

Figure 3. Impact of overexpressing $A a P E P C 1$ on photosynthetic rate $(\mathbf{a})$, carbon isotope ratio $\delta^{13} \mathrm{C}(\mathbf{b})$, malate content $(\mathbf{c})$, and glucose content (d) in tobacco. OE1 and OE2: the transgenic plants expressing AaPEPC1. EV: empty vector control. WT: wild-type plants. White and black bars indicate the light period (12 h) and the dark period (12 h), respectively. X-axis represents the time after the beginning of the light period at 00:00 $\mathrm{h}$. Values represent means $\pm \mathrm{SD}(\mathrm{n}=3$ individual replicate plants). * and ** indicated significant difference from that of WT at $p<0.05$ and $p<0.01$, respectively, by one-way ANOVA analysis with a post-hoc Tukey honestly significant difference (HSD) test. Ns = non-significant.

\subsection{CAM-Related Genes Were Up-Regulated by AaPEPC1 Overexpression}

To test whether the re-programed changes in diel malate and glucose content led to feedback regulation of CAM pathway genes, the transcript abundance of the orthologs of CAM genes in the transgenic and WT plants was analyzed using qRT-PCR (Figure 4a). The expression of carbonic anhydrase (NsyCA), an ortholog of CA that is responsible for rapid interconversion of $\mathrm{CO}_{2}$ and $\mathrm{HCO}_{3}{ }^{-}$in $\mathrm{CAM}$, was more increased in transgenic plants expressing AaPEPC1 compared with that in the controls at 9, 15 and $21 \mathrm{~h}$ after the beginning of the light period (Figure $4 \mathrm{~b}$ ). The expression levels of malate dehydrogenase $(N s y M D H)$ (an ortholog of MDH that is responsible for catalyzing the oxidation of malate to OAA in CAM) and tonoplast aluminum-activated malate transporter (NsyALMT) (an ortholog of ALMT that is responsible for transporting malate into vacuole in CAM) in the transgenic plants expressing AaPEPC1 were higher than those in the controls at the early night period ( $15 \mathrm{~h}$ after the beginning of the light period)(Figure $4 \mathrm{c}, \mathrm{d})$. The expression of tonoplast dicarboxylate transporter (NsyTDT) (an ortholog of TDT that may be responsible for transporting malic acid out of vacuole in CAM) was up-regulated in transgenic plants expressing AaPEPC1 at the early morning period ( $3 \mathrm{~h}$ after the beginning of the light period) (Figure 4e). The expression level of malic enzyme (NsyME) (an ortholog of ME that may be responsible for the decarboxylation of malate in CAM species) in transgenic AaPEPC1 
plants was increased during the light period (Figure 4f). These results demonstrated that the overexpression of the AaPEPC1 up-regulates the expression of the orthologs of CAM pathway genes in transgenic plants.

a
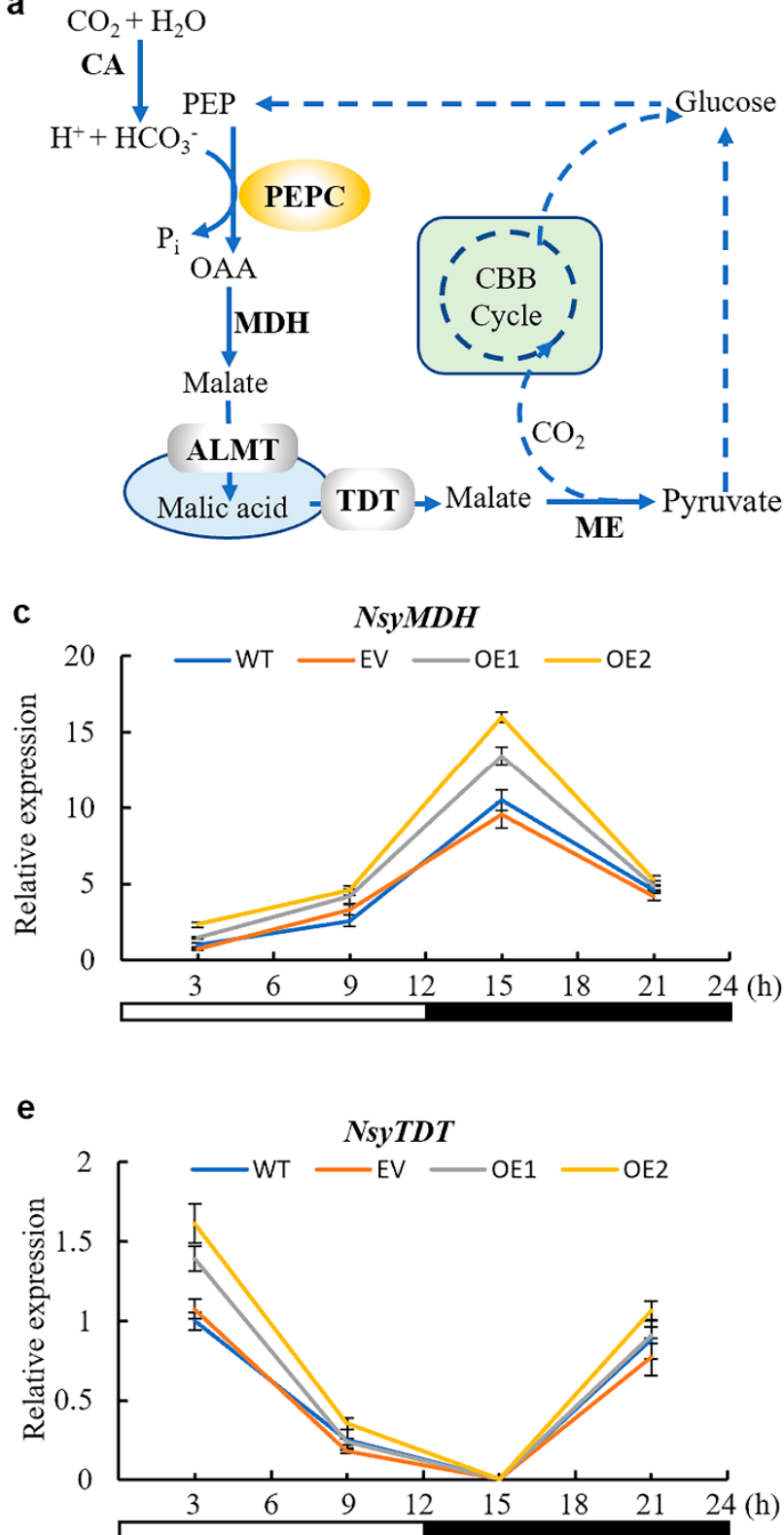

b

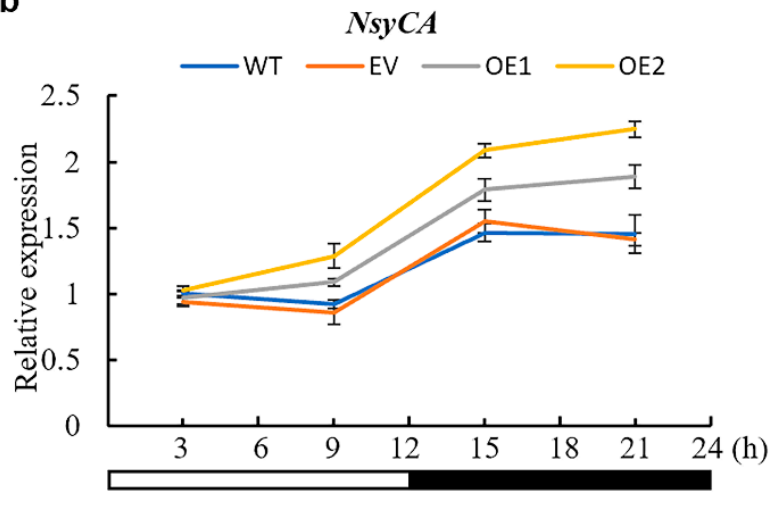

d

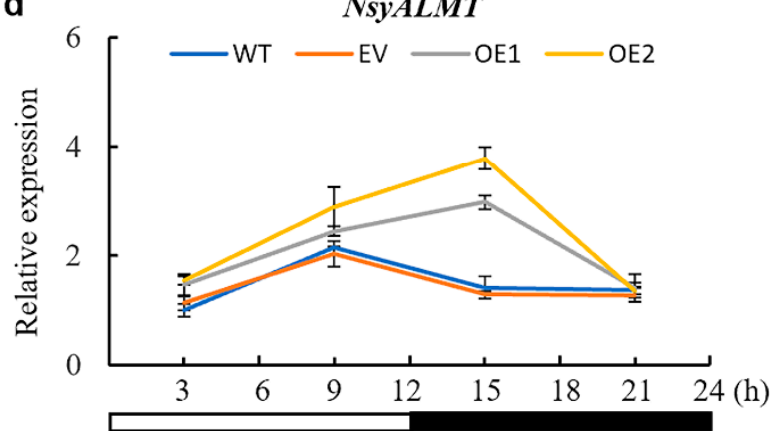

f

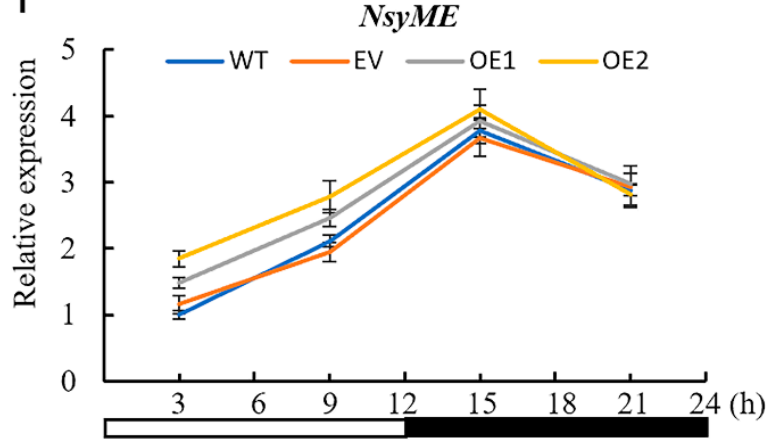

Figure 4. Relative expression level of the orthologs of CAM pathway genes in AaPEPC1-overexpressing tobacco plants. (a) Diagram of the CAM pathway in malic enzyme (ME) subtype [24]. CA: carbonic anhydrase; PEPC: phosphoenolpyruvate carboxylase; OAA: oxaloacetate; $\mathrm{MDH}$ : malate dehydrogenase; ALMT: aluminum-activated malate transporter; TDT: tonoplast dicarboxylate transporter; CBB: Calvin-Benson-Bassham. (b-f) Relative expression level of Nicotiana sylvestris CA (NsyCA, XM_009805732.1), NsyMDH (XM_009784202.1), NsyALMT (XM_009797046.1), NsyTDT, (XM_009797970.1) and NsyME (XM_009781546.1), respectively. The actin gene (XM_009774717.1) was used as an internal control. The values were normalized to expression in the wild-type plants (WT) at the $3 \mathrm{~h}$ light time-point. White and black bars indicate daytime $(12 \mathrm{~h})$ and nighttime $(12 \mathrm{~h})$, respectively. $X$-axis represents the time after the beginning of the light period. Values represent means $\pm \operatorname{SD}(\mathrm{n}=3)$. 


\subsection{Impact of AaPEPC1 Overexpression on Biomass Production}

Based on the above, we speculated that the higher photosynthetic rates, glucose content and carbon isotope ratio $\delta^{13} \mathrm{C}$ measured in transgenic plants overexpressing AaPEPC1 may result in improved biomass production. To test this, we examined the growth of the transgenic plants overexpressing AaPEPC1, along with the EV and WT control plants, in growth chambers under well-water conditions. After six weeks of growth, the transgenic $A a P E P C 1$ plants exhibited larger physical size than the WT and EV controls (Figure 5a). The dry weight of the transgenic AaPEPC1 plants was significantly increased in comparison with the control plants (Figure $5 \mathrm{~b}$ ), demonstrating that $A a P E P C 1$ overexpression increases biomass production in transgenic plants under normal conditions.

a

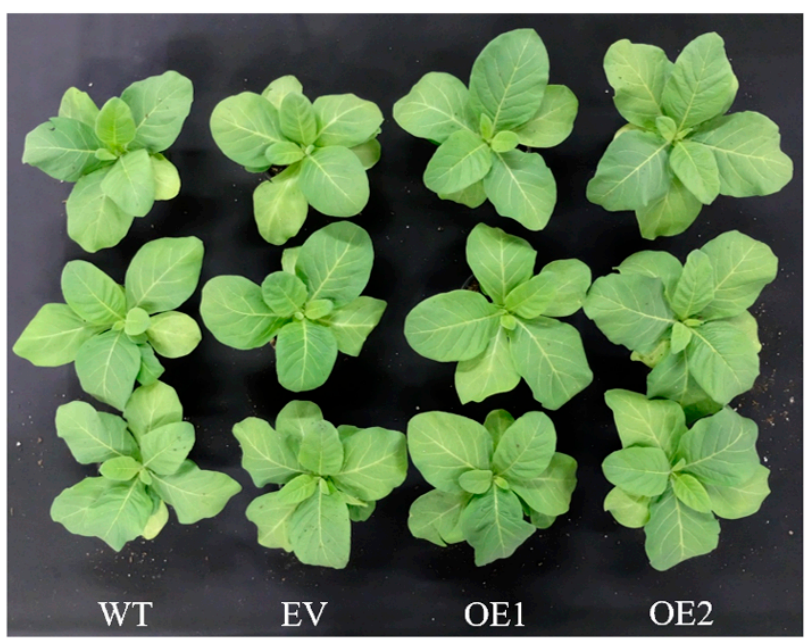

b

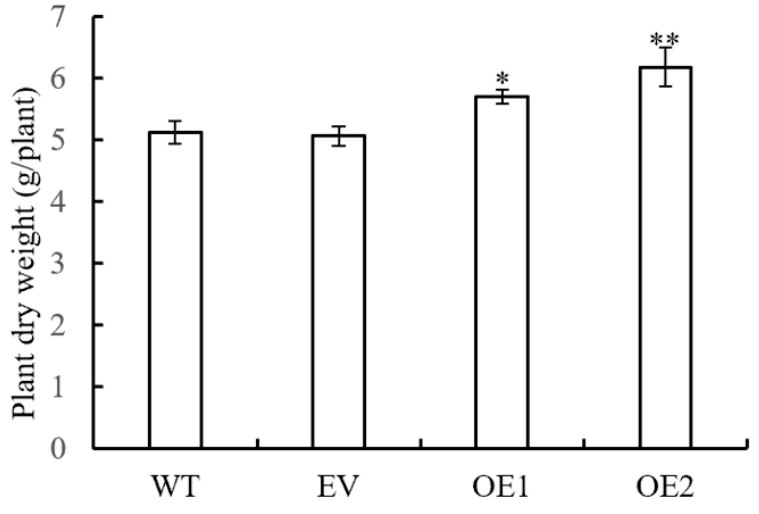

Figure 5. Growth characteristics of transgenic tobacco plants expressing AaPEPC1. (a) Phenotypes of transgenic plants expressing AaPEPC1 (OE1 and OE2) as well as empty vector (EV), and wild-type plants (WT), grown in pots for 6 weeks under well-watered conditions. (b) Dry weight (shoot and root) of transgenic plants and WT. Values represent means \pm SD $(\mathrm{n}=3){ }^{*}$ and ${ }^{* *}$ indicate significant difference from that of WT at $p<0.05$ and $p<0.01$, respectively, by one-way ANOVA analysis with post-hoc Tukey HSD.

\subsection{Impact of AaPEPC1 Overexpression on Salt and Drought Tolerance}

Most crop plants are susceptible to salinity. The $\mathrm{NaCl}$ stress at concentrations of 100-200 mM can inhibit or even completely prevent plant growth, resulting in their death [57,58]. To investigate whether the overexpression of AaPEPC1 enhanced salt tolerance in transgenic plants, the transgenic AaPEPC1 plants as well as the EV and WT controls were grown in pots and irrigated with $200 \mathrm{~mL}$ of $200 \mathrm{mM} \mathrm{NaCl}$ solution once every two days for four weeks. The salt-stress treatment caused the death of the WT and EV control plants, while the transgenic plants overexpressing AaPEPC1 maintained growth (Figure 6a). The dry weight of the transgenic plants overexpressing AaPEPC1 was significantly increased compared to the controls (Figure 6b), establishing that the overexpression of AaPEPC1 significantly enhanced tolerance to salt stress in transgenic tobacco plants.

To investigate whether overexpression of AaPEPC1 enhanced drought tolerance in transgenic plants, the transgenic AaPEPC1 plants, and EV and WT controls, were subjected to drought stress in growth chamber condition. After 15 days without watering, all WT and EV control plants displayed severe wilting (all leaves were severely curled and most leaves had turned yellow / or were dead), whereas the growth of transgenic tobacco plants expressing AaPEPC1 was less affected and their youngest leaves were still green and expanded (Figure 7a). Three days after re-watering, all WT and EV controls were nearly dead, whereas all transgenic lines expressing AaPEPC1 survived and started to regrow (Figure 7b). Dry weight of the transgenic plants expressing AaPEPC1 was also significantly increased 
compared to the WT and EV controls (Figure 7c), providing evidence that overexpression of $A a P E P C 1$ improved the drought tolerance in the transgenic tobacco plants.

$\mathbf{a}$

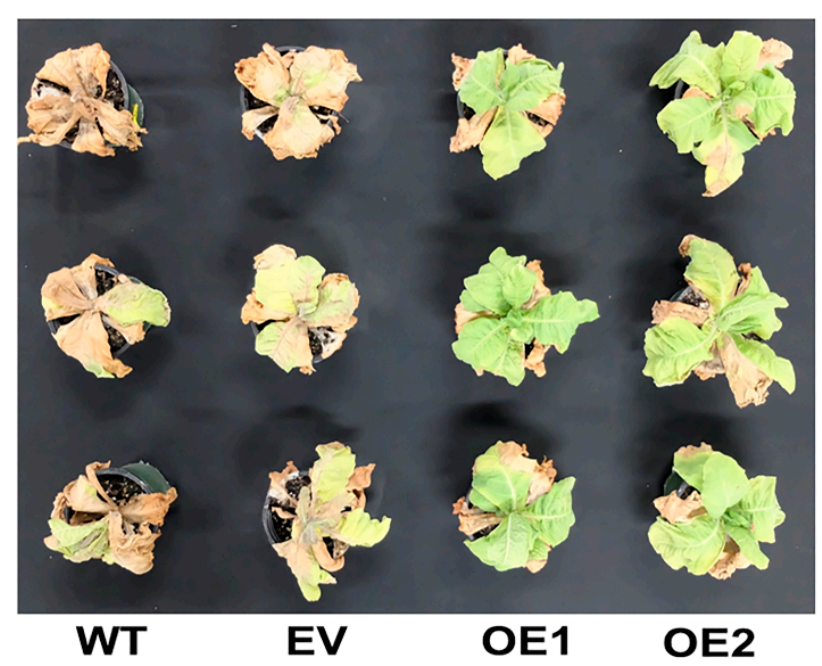

b

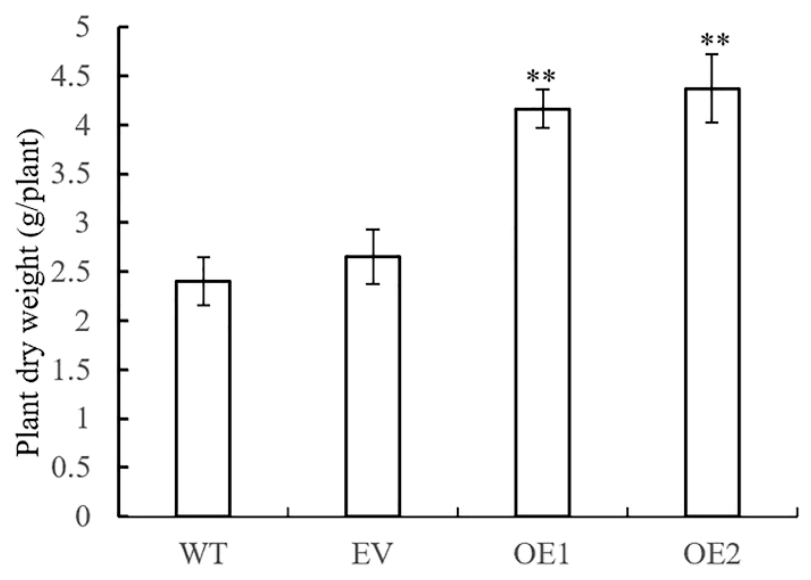

Figure 6. Responses of the AaPEPC1-overexpressing tobacco plants under salt stress. (a) Phenotypes of transgenic plants expressing AaPEPC1 (OE1, OE2) or empty vector (EV), and wild-type plants (WT) grown in pots under $200 \mathrm{mM} \mathrm{NaCl}$ stress. The plants were irrigated with $200 \mathrm{mM} \mathrm{NaCl}$ solution once every 2 days for 4 weeks. (b) Dry weight of transgenic plants and WT. Values represent means $\pm \mathrm{SD}(\mathrm{n}=3)$. ${ }^{* *}$ significant difference from that of WT $p<0.01$, by one-way ANOVA analysis with post-hoc Tukey HSD.

a

15 days without watering

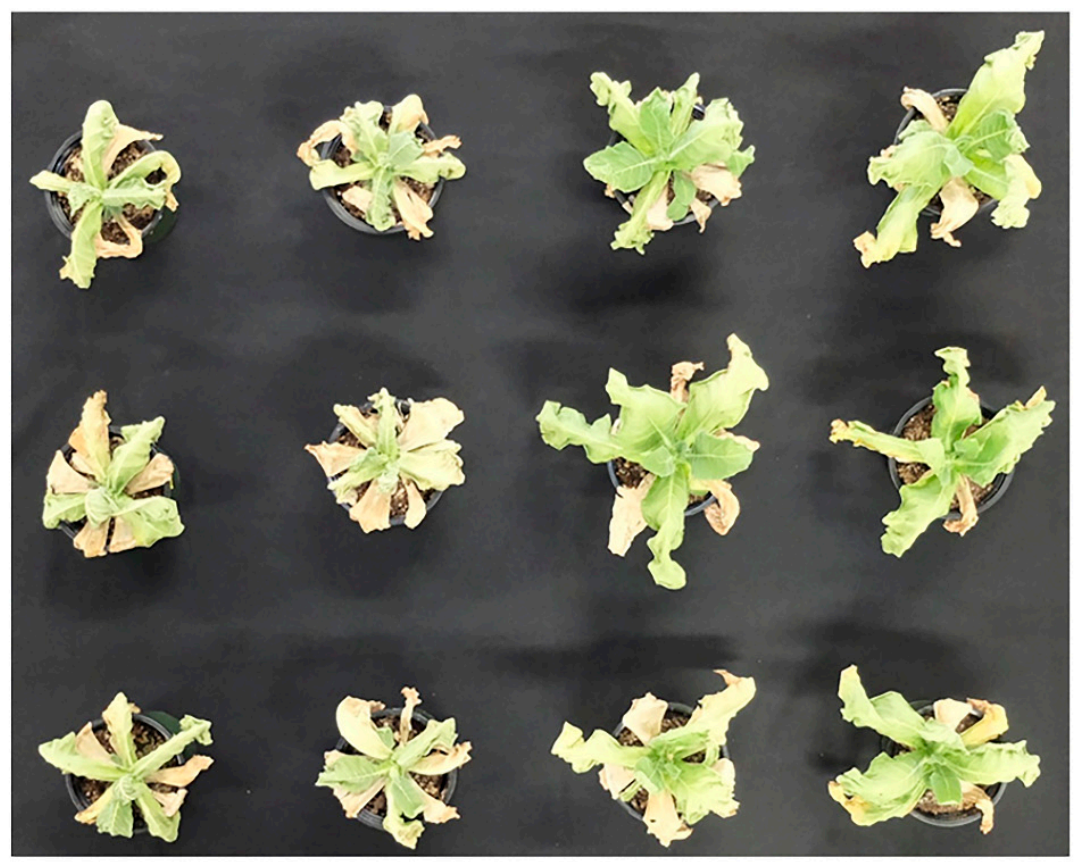

Figure 7. Cont. 
b

3 days after rewatering

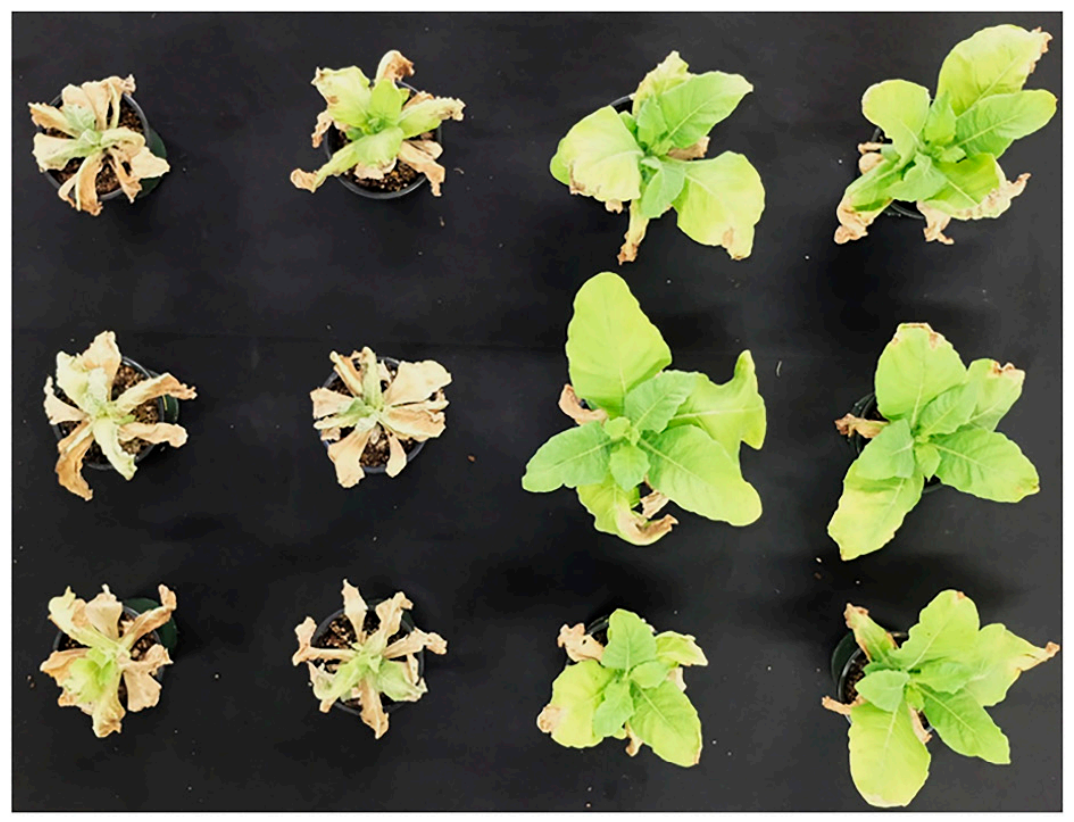

WT

EV

\section{OE1 OE2}

C

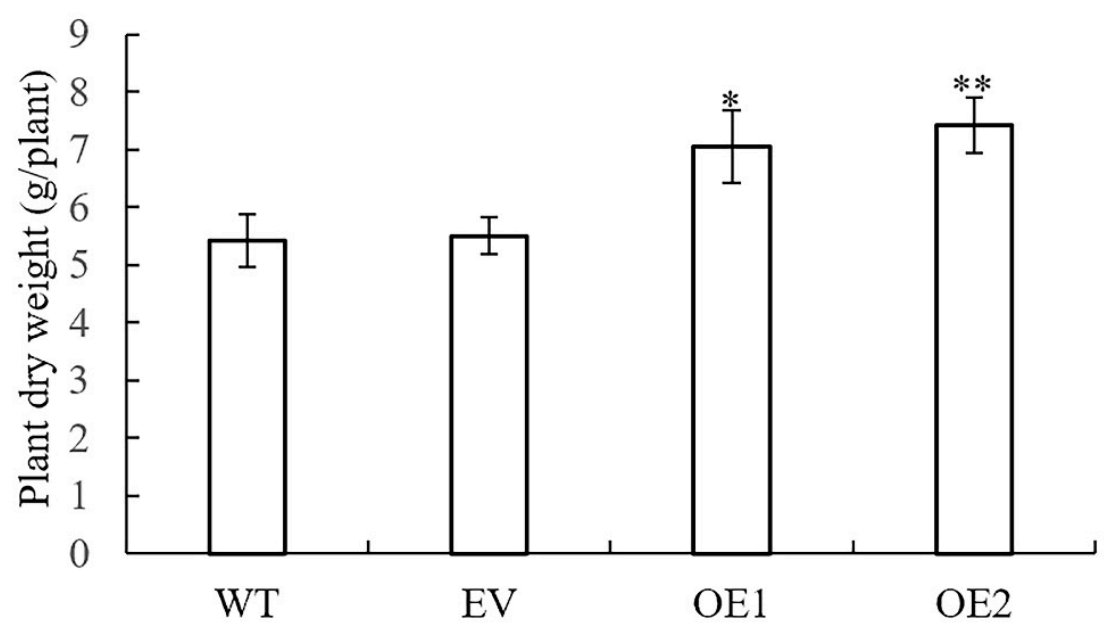

Figure 7. Responses of the AaPEPC1-overexpressing tobacco plants under drought stress. Phenotypes of transgenic plants expressing AaPEPC1 (OE1 and OE2) or as well as empty vector (EV), and wild-type plants (WT) grown in pots under drought stress (a) and after re-watering (b). Transgenic and WT were grown in soil for 15 days without watering. (c) Dry weight of transgenic and WT plants. Values represent means $\pm \mathrm{SD}(\mathrm{n}=3)$. * and ** indicate significant difference from that of WT at $p<0.05$ and $p<0.01$, respectively, by one-way ANOVA analysis with post-hoc Tukey HSD.

\subsection{Proline Biosynthesis Is Enhanced by AaPEPC1 Overexpression}

PEPC plays a crucial role in nitrogen metabolism in Arabidopsis [47] and loss-offunction of both PEPC1 and PEPC2 decreased the levels of glutamate in Arabidopsis. Glutamate can be converted into proline through pyrroline-5-carboxylate synthase (P5CS) and pyrroline-5-carboxylate reductase (P5CR) [11]. Proline plays important roles in stress tolerance, e.g., drought and salt stress tolerance, by regulating osmotic balance, activating the ROS scavenging system, protecting membrane integrity and photosynthesis $[11,59]$. We hypothesized that overexpression of AaPEPC1 could enhance proline biosynthesis, and consequently increase the drought and salt stress tolerance in the transgenic plants. To test this hypothesis, proline content was analyzed in the transgenic AaPEPC1 plants, along with the WT and EV controls. The proline contents in the transgenic plants expressing AaPEPC1 
were significantly higher than that in the WT and EV controls (Figure 8a). Furthermore, the expression levels of two key proline biosynthesis genes NsyP5CS and NsyP5CR were significantly higher in the transgenic AaPEPC1 plants in comparison with the WT and EV controls (Figure 8b,c), supporting our hypothesis that the overexpression of AaPEPC1 increased drought and salt stress tolerance through the enhancement of proline biosynthesis.

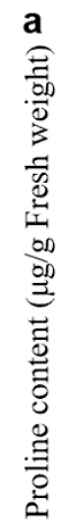
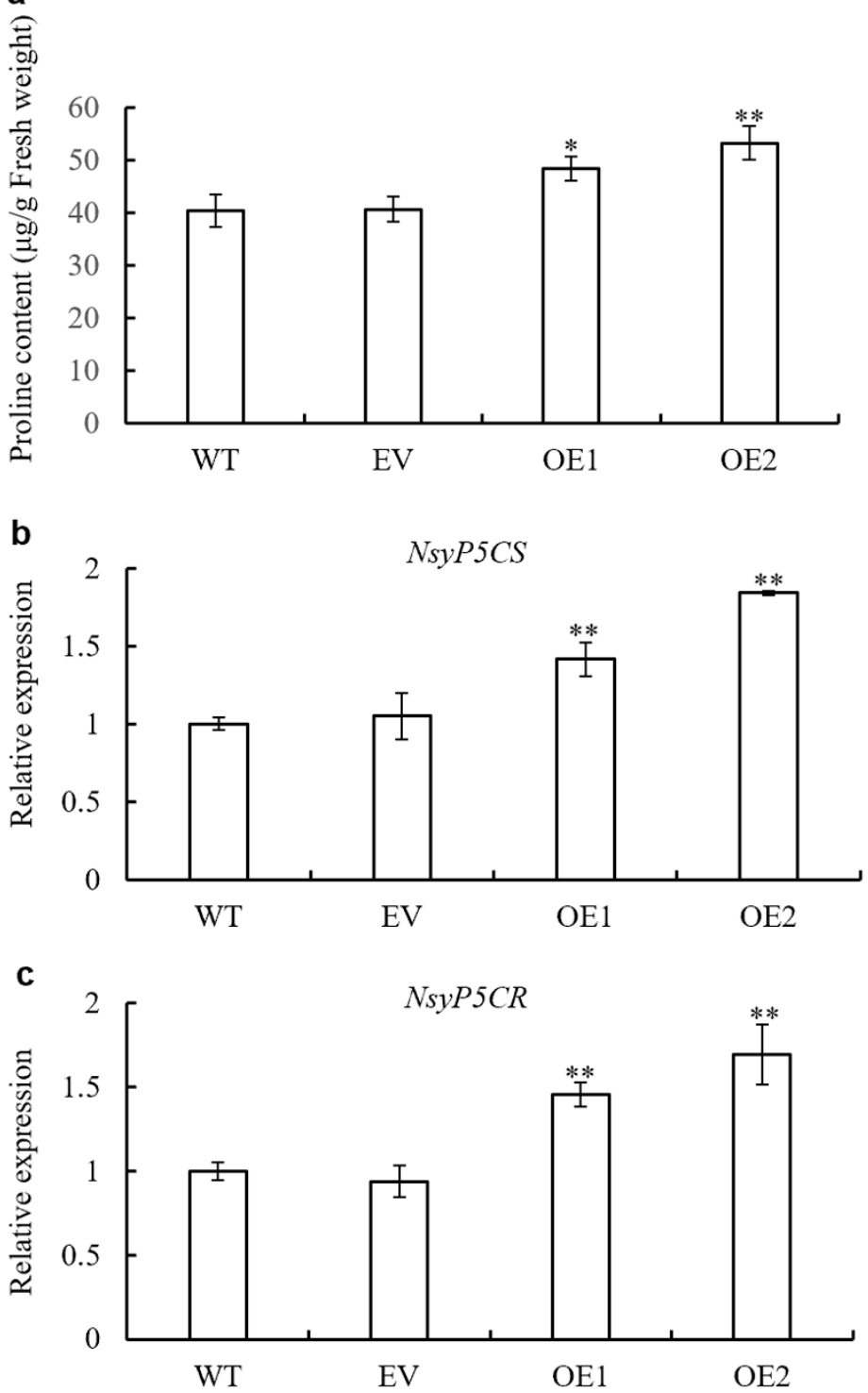

Figure 8. Changes in proline biosynthesis in AaPEPC1-overexpressing tobacco plants. (a) Proline content in the leaves of transgenic plants expressing AaPEPC1 (OE1 and OE2) as well as empty vector (EV), and wild-type plants (WT). (b) and (c) Relative expression level of the proline biosynthesis genes pyrroline-5-carboxylate synthase (P5CS) and pyrroline-5-carboxylate reductase (P5CR) in the AaPEPC1-overexpressing tobacco plants. Values represent means $\pm \mathrm{SD}(\mathrm{n}=3) .{ }^{*}$ and ${ }^{* *}$ indicate significant difference from that of WT at $p<0.05$ and $p<0.01$, respectively, by one-way ANOVA analysis with post-hoc Tukey HSD.

\section{Discussion}

The engineering of the water-conserving $\mathrm{CO}_{2}$-concentrating mechanism of $\mathrm{CAM}$ has been proposed as a potential strategy for improving photosynthetic $\mathrm{CO}_{2}$ fixation and abiotic stress tolerance in $C_{3}$ plants $[1,2,9]$. In this study, we found that the overexpression of one single CAM gene AaPEPC1 enhanced the performance of transgenic plants in multiple ways, including photosynthesis, biomass production, drought tolerance and 
salt tolerance, which yet not be reported. We determined the impacts of the ectopic expression of the $A a P E P C 1$ on $\mathrm{C}_{3}$-toward-CAM progression. Specifically, we identified a CAM-type PEPC (AaPEPC1) in A. americana and transformed the AaPEPC1 gene into $\mathrm{C}_{3}$ plant tobacco. Compared with the WT and EV controls, the transgenic plants expressing $A a P E P C 1$ showed several interesting traits: (1) a higher malate content at the onset of the dark period, (2) higher leaf carbon isotope ratios $\left(\delta^{13} \mathrm{C}\right.$ values), and (3) upregulated expression levels of the orthologs of several putative key CAM pathway genes (Figures 3 and 4). These changes in photosynthetic carbon metabolism driven by AaPEPC1 improved photosynthetic $\mathrm{CO}_{2}$-fixation, biomass production and tolerance to drought and salt stresses (Figure 9). These traits are not necessarily associated with CAM. Recently, Boxall, et al. [60] silenced PEPC1 in a CAM plant species Kalanchoë laxiflora and found that the very low level of PEPC activity in the RNAi transgenic line was associated with the refixation of respiratory $\mathrm{CO}_{2}$ and malate accumulation. Daloso, et al. [61] reported that tobacco guard cells fix $\mathrm{CO}_{2}$ by both Rubisco and PEPC. The photosynthetic carbon metabolism changes in our study could be explained by PEPC-mediated $\mathrm{CO}_{2}$ fixation during the light period or the refixation of respiratory $\mathrm{CO}_{2}$, or an enhanced anaplerotic role for PEPC as in $\mathrm{C}_{3}$ plants. $\mathrm{A} \mathrm{CO}_{2}$ labeled assay and metabolites analysis could be used to test this hypothesis and to identify the possible secondary products arising from PEPC overexpression in the future. Metabolite (e.g., glucose) sensing and signaling play important roles in regulating gene expression and controlling plant development $[62,63]$. We hypothesize that AaPEPC1 overexpression perturbated the expression levels of metabolite signaling genes which subsequently caused the phenotypic changes (e.g., drought stress tolerance) in the transgenic tobacco plants. We found that the glucose, malate and proline contents were increased, and a few CAM-related genes were upregulated in the transgenic plants overexpressing $A a P E P C 1$. Glucose, as a reducing sugar, is only ever present in modest concentrations, thus representing the partitioning of primary photosynthate or trafficking of reserves. A full starch-glucan-sucrose digestion could be performed to comprehensively evaluate the carbohydrate status in transgenic plants, and an integrative analysis of metabolomics, transcriptomics and proteomics could help to test this hypothesis in the future. This initial success provides a solid foundation for future effort to achieve a complete switch from $\mathrm{C}_{3}$ to CAM photosynthesis by engineering additional CAM-related genes involved in carboxylation, decarboxylation, stomatal movement, the glycolytic-gluconeogenic pathway and carbohydrate turnover modules [1,2,9].

It is interesting that $A a P E P C 1$ overexpression increased the transcript abundance of several other CAM-related genes, including $C A, M D H, A L M T$, TDT and $M E$ (Figure 4). As a $\mathrm{CO}_{2}$-fixation enzyme, AaPEPC1 is not able to directly regulate the expression of other genes at the transcription level. We hypothesize that the change in cellular metabolic status caused by the AaPEPC1 overexpression resulted in a rewiring of the regulatory network. This hypothesis can be tested through the transcriptomic and metabolomic analysis of gainof-function and loss-of-function AaPEPC1 mutants in the future. It was recently reported that phosphorylation of PEPC is essential for core circadian clock operation in the obligate CAM species Kalanchoë fedtschenkoi [20]. Therefore, it would be interesting to investigate the impact of $A a P E P C 1$ overexpression on the circadian rhythm in the transgenic plants in the future. In addition, on the premise of the coordinated regulation of multiple CAM-related genes by overexpressing one key gene such as $A a P E P C 1$, we can argue that there is no need to transfer all the CAM pathway genes into $C_{3}$ species; consequently, we just need to focus on the engineering of a small number of "master" genes like AaPEPC1, which can upregulate the expression of multiple other CAM-related genes. 


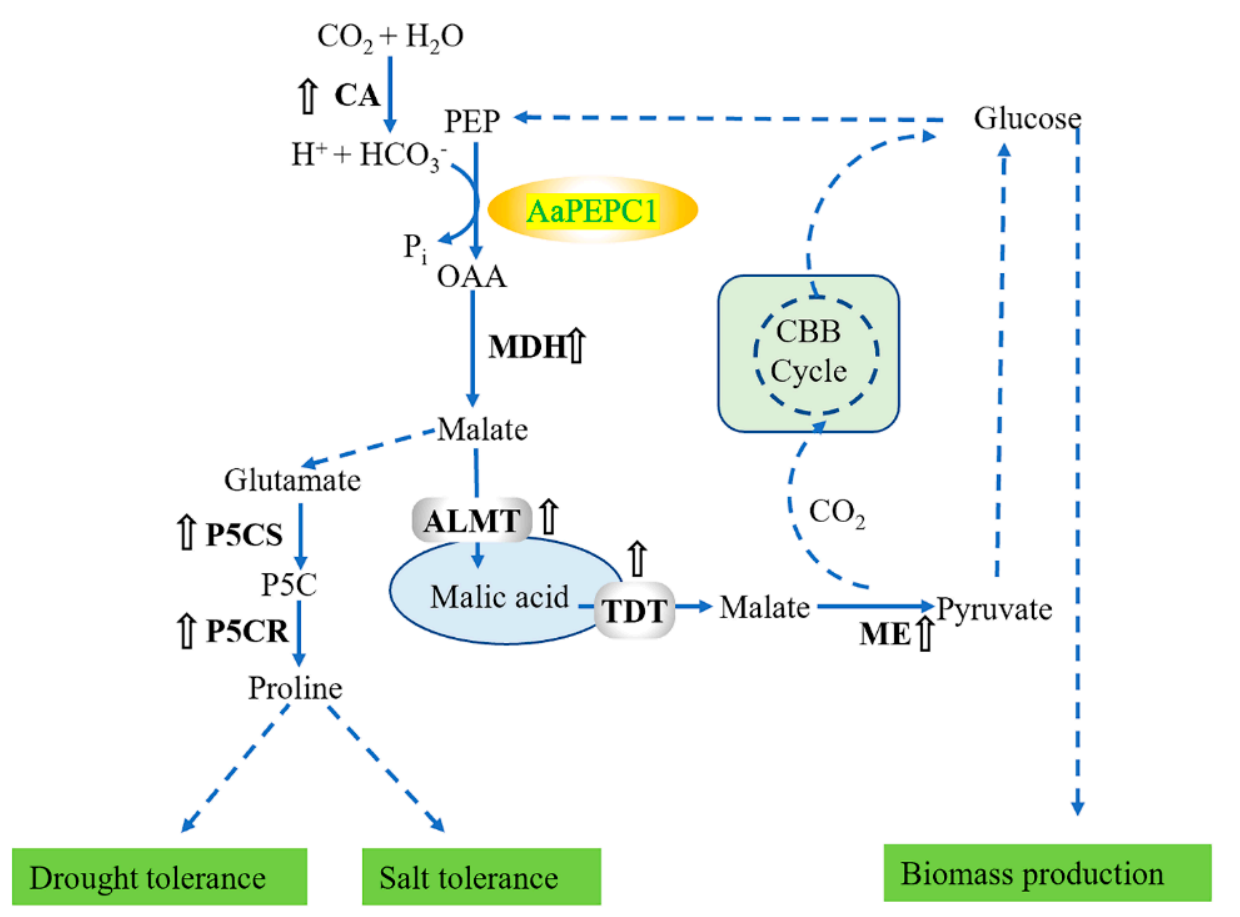

Figure 9. Regulation of photosynthetic $\mathrm{CO}_{2}$-fixation and abiotic stress tolerance in the 'turbocharging' plants with the AaPEPC1. Overexpression of the AaPEPC1, a highly abundant enzyme catalyzing the primary fixation of $\mathrm{CO}_{2}$ in $\mathrm{CAM}$ plants, increases photosynthetic $\mathrm{CO}_{2}$-fixation, and rewires the diel accumulation-depletion pattern of malate and glucose. The re-programed malate-dependent carboxylation leads to the feedback up-regulation of the orthologs of key CAM pathway genes, i.e., nocturnal carboxylation and diurnal decarboxylation modules. The increased malate content up-regulates pyrroline-5-carboxylate synthase (P5CS) and pyrroline-5-carboxylate reductase (P5CR), which results in higher proline accumulation. Proline accumulation enhances the salt and drought tolerance of the transgenic plants expressing AaPEPC1. Additionally, a higher glucose content produced from the photosynthetic source is transported as sucrose or glucose to sink tissues and organs to promote cell proliferation, elongation, and expansion, as well as to maintain energy and metabolic homeostasis, resulting in improved biomass production $[64,65]$. The up arrows indicate up-regulation of expression of genes coding these enzymes or content. CA: carbonic anhydrase; OAA: oxaloacetate; MDH: malate dehydrogenase; ALMT: aluminum-activated malate transporter; TDT: tonoplast dicarboxylate transporter; ME: malic enzyme; PEP: phosphoenolpyruvate; and CBB: Calvin-Benson-Bassham.

Although PEPC is well-known as a key enzyme for $\mathrm{CO}_{2}$ fixation, its role in conferring resistance to salt stress in plants is not well defined [66]. In this study, we demonstrated that the overexpression of $A a P E P C 1$ significantly increased the salt tolerance in transgenic tobacco plants (Figure 6), likely a result of enhanced biosynthesis of proline (Figure 8), which plays important roles in regulating osmotic balance, activating ROS scavenging system, protecting membrane integrity and photosynthesis [11]. $\mathrm{C}_{4}$-type PEPC and $\mathrm{C}_{3}$-type PEPC have also been reported to be involved in drought tolerance improvement [67,68], but the mechanism is unclear. Thus far, the role of CAM-type PEPC in drought tolerance has not been reported yet. In this study, we found that overexpression of the AaPEPC1 significantly increased the drought tolerance in the transgenic tobacco plants (Figure 7). Our results suggested that the improvement of photosynthetic carbon metabolism in the transgenic AaPEPC1 plants enhanced proline metabolism pathway, which results in improved drought tolerance (Figure 9). In addition, compared to the previously published work for $\mathrm{C}_{4}$-type PEPC or $\mathrm{C}_{3}$-type PEPC overexpression in plants [67-70], this is the first time it has been shown that overexpression of one single PEPC gene enables the simultaneous improvement of photosynthesis and stress tolerance in plants. 
Recently, photosynthesis and plant growth were significantly improved in tobacco plants by introducing a faster Rubisco of cyanobacterial origin [71], accelerating recovery from photoprotection [72], or engineering synthetic glycolate metabolism pathways [5]. However, none of these approaches enhanced tolerance to drought or salt stresses. In addition, previous genetic engineering efforts have reported progress in creating geneticallymodified plants with enhanced tolerance to either drought stress [73,74] or salt stress [75-77], with limited success in conferring tolerance to both drought stress and salt stress in a single transgenic line. In this study, we created genetically modified tobacco plants that had enhanced performance in multiple aspects: photosynthesis, plant growth, drought tolerance, and salt tolerance. As such, we have provided new insights into the concept that the coordinated regulation of photosynthesis can increase biomass and stress tolerance [78]. These pleiotropic effects of AaPEPC1-overexpression open a new door to genetic improvement of crops for sustainable bioenergy and food production on marginal lands to alleviate the challenge caused by human population growth, urbanization, and global climate change.

In conclusion, we report the first successful effort of the engineering of a CAM pathway gene to improve photosynthetic $\mathrm{CO}_{2}$ fixation and abiotic stress tolerance in tobacco, the model $C_{3}$ plant species. These findings have important implications for ultimate aspirations to engineer CAM into non-CAM crops as a means of improving productivity, and abiotic stress tolerance.

Supplementary Materials: The following are available online at https:/ /www.mdpi.com/2073-4 409/10/3/582/s1, Figure S1: Development of transgenic lines of tobacco overexpressing Agave americana PHOSPHOENOLPYRUVATE CARBOXYLASE (AaPEPC1); Figure S2: Chlorophyll relative content in the leaves of transgenic plants expressing Agave americana PHOSPHOENOLPYRUVATE CARBOXYLASE (AaPEPC1) (OE1, OE2) or empty vector (EV), and wild-types (WT) grown in pots under normal growth conditions. Table S1: Primers used in this study.

Author Contributions: X.Y. conceived, designed and supervised the project, as well as edited the manuscript. D.L. conceived, designed and performed the experiments, as well as wrote the manuscript. R.H. designed and constructed the AaPEPC1 binary vector, performed molecular identification of transgenic plants and screened homozygous lines. J.Z. performed genome-wide analysis of the PEPC gene family and phylogenetic analysis. H.-B.G. and H.Q. performed structural modeling and molecular dynamics simulation analysis. H.C. performed the experiments. L.L. interpreted the data. G.A.T., A.M.B., J.-G.C. and W.M. reviewed and edited the manuscript. All authors have read and agreed to the published version of the manuscript.

Funding: This research is supported by the U.S. Department of Energy (DOE), Office of Science, Genomic Science Program under Award Number DE-SC0008834, and the Center for Bioenergy Innovation (CBI), which is a DOE Bioenergy Research Center supported by the Biological and Environmental Research program in the DOE Office of Science. Oak Ridge National Laboratory is managed by UT-Battelle, LLC for the DOE under Contract Number DE-AC05-00OR22725. HG and HQ also acknowledge the support of NSF Career award \#1453078 (transferred to \#1720215), BD Spoke \#1761839, and internal funding of University of Tennessee at Chattanooga.

Informed Consent Statement: Not applicable.

Data Availability Statement: Data presented in this study are contained in this article, or available upon request to the corresponding author.

Conflicts of Interest: The authors declare no conflict of interest.

Additional Information: This manuscript has been authored by UT-Battelle, LLC under Contract No. DE-AC05-00OR22725 with the U.S. Department of Energy. The United States Government retains and the publisher, by accepting the article for publication, acknowledges that the United States Government retains a non-exclusive, paid-up, irrevocable, world-wide license to publish or reproduce the published form of this manuscript, or allow others to do so, for United States Government purposes. The Department of Energy will provide public access to these results of federally sponsored research in accordance with the DOE Public Access Plan (http:/ /energy.gov/ downloads/doe-public-access-plan). 


\section{References}

1. Yang, X.; Cushman, J.C.; Borland, A.M.; Edwards, E.J.; Wullschleger, S.D.; Tuskan, G.A.; Owen, N.A.; Griffiths, H.; Smith, J.A.C.; De Paoli, H.C. A roadmap for research on crassulacean acid metabolism (CAM) to enhance sustainable food and bioenergy production in a hotter, drier world. New Phytol. 2015, 207, 491-504. [CrossRef]

2. Liu, D.; Palla, K.J.; Hu, R.; Moseley, R.C.; Mendoza, C.; Chen, M.; Abraham, P.E.; Labbé, J.L.; Kalluri, U.C.; Tschaplinski, T.J. Perspectives on the basic and applied aspects of crassulacean acid metabolism (CAM) research. Plant Sci. 2018, 274, $394-401$. [CrossRef] [PubMed]

3. Hanjra, M.A.; Qureshi, M.E. Global water crisis and future food security in an era of climate change. Food Policy 2010, 35, 365-377. [CrossRef]

4. Godfray, H.C.J.; Beddington, J.R.; Crute, I.R.; Haddad, L.; Lawrence, D.; Muir, J.F.; Pretty, J.; Robinson, S.; Thomas, S.M.; Toulmin, C. Food security: The challenge of feeding 9 billion people. Science 2010, 327, 812-818. [CrossRef]

5. South, P.F.; Cavanagh, A.P.; Liu, H.W.; Ort, D.R. Synthetic glycolate metabolism pathways stimulate crop growth and productivity in the field. Science 2019, 363, eaat9077. [CrossRef] [PubMed]

6. Salesse-Smith, C.E.; Sharwood, R.E.; Busch, F.A.; Kromdijk, J.; Bardal, V.; Stern, D.B. Overexpression of Rubisco subunits with RAF1 increases Rubisco content in maize. Nat. Plants 2018, 4, 802. [CrossRef]

7. Hibberd, J.M.; Sheehy, J.E.; Langdale, J.A. Using $C_{4}$ photosynthesis to increase the yield of rice-Rationale and feasibility. Curr. Opin. Plant Biol. 2008, 11, 228-231. [CrossRef]

8. Shameer, S.; Baghalian, K.; Cheung, C.M.; Ratcliffe, R.G.; Sweetlove, L.J. Computational analysis of the productivity potential of CAM. Nat. Plants 2018, 4, 165. [CrossRef] [PubMed]

9. Borland, A.M.; Hartwell, J.; Weston, D.J.; Schlauch, K.A.; Tschaplinski, T.J.; Tuskan, G.A.; Yang, X.; Cushman, J.C. Engineering crassulacean acid metabolism to improve water-use efficiency. Trends Plant Sci. 2014, 19, 327-338. [CrossRef] [PubMed]

10. Mahmood, T.; Khalid, S.; Abdullah, M.; Ahmed, Z.; Shah, M.K.N.; Ghafoor, A.; Du, X. Insights into drought stress signaling in plants and the molecular genetic basis of cotton drought tolerance. Cells 2019, 9, 105. [CrossRef] [PubMed]

11. Liu, D.; He, S.; Zhai, H.; Wang, L.; Zhao, Y.; Wang, B.; Li, R.; Liu, Q. Overexpression of IbP5CR enhances salt tolerance in transgenic sweetpotato. Plant Cell. Tissue Organ Cult. 2013, 117, 1-16. [CrossRef]

12. Zhai, H.; Wang, F.; Si, Z.; Huo, J.; Xing, L.; An, Y.; He, S.; Liu, Q. A myo-inositol-1-phosphate synthase gene, IbMIPS1, enhances salt and drought tolerance and stem nematode resistance in transgenic sweet potato. Plant Biotechnol. J. 2016, 14, 592-602. [CrossRef] [PubMed]

13. Ahmed, I.M.; Nadira, U.A.; Qiu, C.-W.; Cao, F.; Chen, Z.-H.; Vincze, E.; Wu, F. The barley S-adenosylmethionine synthetase 3 gene HvSAMS3 positively regulates the tolerance to combined drought and salinity stress in Tibetan wild barley. Cells 2020, 9 , 1530. [CrossRef]

14. Movafeghi, A.; Khataee, A.; Abedi, M.; Tarrahi, R.; Dadpour, M.; Vafaei, F. Effects of $\mathrm{TiO}_{2}$ nanoparticles on the aquatic plant Spirodela polyrrhiza: Evaluation of growth parameters, pigment contents and antioxidant enzyme activities. J. Environ. Sci. 2018, 64, 130-138. [CrossRef] [PubMed]

15. Tarrahi, R.; Khataee, A.; Movafeghi, A.; Rezanejad, F.; Gohari, G. Toxicological implications of selenium nanoparticles with different coatings along with $\mathrm{Se}^{4+}$ on Lemna minor. Chemosphere 2017, 181, 655-665. [CrossRef] [PubMed]

16. Turbat, A.; Rakk, D.; Vigneshwari, A.; Kocsubé, S.; Thu, H.; Szepesi, Á.; Bakacsy, L.; D Škrbić, B.; Jigjiddorj, E.-A.; Vágvölgyi, C. Characterization of the plant growth-promoting activities of endophytic fungi isolated from Sophora flavescens. Microorganisms 2020, 8, 683. [CrossRef]

17. Ehleringer, J.R.; Monson, R.K. Evolutionary and ecological aspects of photosynthetic pathway variation. Annu. Rev. Ecol. Syst. 1993, 24, 411-439. [CrossRef]

18. Lüttge, U. $\mathrm{CO}_{2}$-concentrating: consequences in crassulacean acid metabolism. J. Exp. Bot. 2002, 53, 2131-2142. [CrossRef]

19. Owen, N.A.; Griffiths, H. A system dynamics model integrating physiology and biochemical regulation predicts extent of crassulacean acid metabolism (CAM) phases. New Phytol. 2013, 200, 1116-1131. [CrossRef]

20. Boxall, S.F.; Dever, L.V.; Knerova, J.; Gould, P.D.; Hartwell, J. Phosphorylation of phosphoenolpyruvate carboxylase is essential for maximal and sustained dark $\mathrm{CO}_{2}$ fixation and core circadian clock operation in the obligate crassulacean acid metabolism species Kalanchoë fedtschenkoi. Plant Cell 2017, 29, 2519-2536. [CrossRef]

21. Eisenhut, M.; Weber, A.P. Improving crop yield. Science 2019, 363, 32-33. [CrossRef]

22. Miyamoto, S. Salt Tolerance of Landscape Plants Common to the Southwest; Texas Water Resources Institute: El Paso, TX, USA, 2008.

23. Davis, S.C.; Kuzmick, E.R.; Niechayev, N.; Hunsaker, D.J. Productivity and water use efficiency of Agave americana in the first field trial as bioenergy feedstock on arid lands. GCB Bioenergy 2016, 9, 314-325. [CrossRef]

24. Yang, X.; Hu, R.; Yin, H.; Jenkins, J.; Shu, S.; Tang, H.; Liu, D.; Weighill, D.A.; Yim, W.C.; Ha, J.; et al. The Kalanchoë genome provides insights into convergent evolution and building blocks of crassulacean acid metabolism. Nat. Commun. 2017, 8, 1899. [CrossRef]

25. Black, C.C.; Osmond, C.B. Crassulacean acid metabolism photosynthesis: 'Working the night shift'. Photosynth. Res. 2003, 76, 329-341. [CrossRef]

26. Klavsen, S.K.; Madsen, T.V.; Maberly, S.C. Crassulacean acid metabolism in the context of other carbon-concentrating mechanisms in freshwater plants: A review. Photosynth. Res. 2011, 109, 269-279. [CrossRef] [PubMed] 
27. Silvera, K.; Neubig, K.M.; Whitten, W.M.; Williams, N.H.; Winter, K.; Cushman, J.C. Evolution along the crassulacean acid metabolism continuum. Funct. Plant Biol. 2010, 37, 995-1010. [CrossRef]

28. Abraham, P.E.; Yin, H.; Borland, A.M.; Weighill, D.; Lim, S.D.; De Paoli, H.C.; Engle, N.; Jones, P.C.; Agh, R.; Weston, D.J.; et al. Transcript, protein and metabolite temporal dynamics in the CAM plant Agave. Nat. Plants 2016, 2, 16178. [CrossRef] [PubMed]

29. Katoh, K.; Rozewicki, J.; Yamada, K.D. MAFFT online service: Multiple sequence alignment, interactive sequence choice and visualization. Brief. Bioinform 2019, 20, 1160-1166. [CrossRef] [PubMed]

30. Trifinopoulos, J.; Nguyen, L.-T.; von Haeseler, A.; Minh, B.Q. W-IQ-TREE: A fast online phylogenetic tool for maximum likelihood analysis. Nucleic Acids Res. 2016, 44, W232-W235. [CrossRef] [PubMed]

31. Masumoto, C.; Miyazawa, S.-I.; Ohkawa, H.; Fukuda, T.; Taniguchi, Y.; Murayama, S.; Kusano, M.; Saito, K.; Fukayama, H.; Miyao, M. Phosphoenolpyruvate carboxylase intrinsically located in the chloroplast of rice plays a crucial role in ammonium assimilation. Proc. Natl. Acad. Sci. USA 2010, 107, 5226-5231. [CrossRef] [PubMed]

32. Roy, A.; Kucukural, A.; Zhang, Y. I-TASSER: A unified platform for automated protein structure and function prediction. Nat. Protoc. 2010, 5, 725-738. [CrossRef] [PubMed]

33. Mirjalili, V.; Noyes, K.; Feig, M. Physics-based protein structure refinement through multiple molecular dynamics trajectories and structure averaging. Proteins 2014, 82, 196-207. [CrossRef] [PubMed]

34. Chen, V.B.; Arendall, W.B.; Headd, J.J.; Keedy, D.A.; Immormino, R.M.; Kapral, G.J.; Murray, L.W.; Richardson, J.S.; Richardson, D.C. MolProbity: All-atom structure validation for macromolecular crystallography. Acta Crystallogr. D 2010, 66, 12-21. [CrossRef] [PubMed]

35. Brooks, B.R.; Brooks, C.L.; Mackerell, A.D.; Nilsson, L.; Petrella, R.J.; Roux, B.; Won, Y.; Archontis, G.; Bartels, C.; Boresch, S.; et al. CHARMM: The biomolecular simulation program. J. Comput. Chem. 2009, 30, 1545-1614. [CrossRef] [PubMed]

36. Phillips, J.C.; Braun, R.; Wang, W.; Gumbart, J.; Tajkhorshid, E.; Villa, E.; Chipot, C.; Skeel, R.D.; Kale, L.; Schulten, K. Scalable molecular dynamics with NAMD. J. Comput. Chem. 2005, 26, 1781-1802. [CrossRef]

37. Best, R.B.; Zhu, X.; Shim, J.; Lopes, P.E.M.; Mittal, J.; Feig, M.; MacKerell, A.D. Optimization of the additive CHARMM all-atom protein force field targeting improved sampling of the backbone phi, psi and Side-Chain chi(1) and chi(2) dihedral angles. $J$. Chem. Theory Comput. 2012, 8, 3257-3273. [CrossRef] [PubMed]

38. Jorgensen, W.L.; Chandrasekhar, J.; Madura, J.D.; Impey, R.W.; Klein, M.L. Comparison of simple potential functions for simulating liquid water. J. Chem. Phys. 1983, 79, 926-935. [CrossRef]

39. Laskowski, R.A.; Jablonska, J.; Pravda, L.; Varekova, R.S.; Thornton, J.M. PDBsum: Structural summaries of PDB entries. Protein Sci. 2018, 27, 129-134. [CrossRef] [PubMed]

40. Terpe, K. Overview of tag protein fusions: from molecular and biochemical fundamentals to commercial systems. Appl. Microbiol. Biot. 2003, 60, 523-533. [CrossRef] [PubMed]

41. Höfgen, R.; Willmitzer, L. Storage of competent cells for Agrobacterium transformation. Nucleic Acids Res. 1988, 16, 9877. [CrossRef]

42. Zhang, L.; Jia, J.; Xu, Y.; Wang, Y.; Hao, J.; Li, T. Production of transgenic Nicotiana sylvestris plants expressing melatonin synthetase genes and their effect on UV-B-induced DNA damage. Vitr. Cell. Dev. Biol. Plant 2011, 48, 275-282. [CrossRef]

43. He, S.; Han, Y.; Wang, Y.; Zhai, H.; Liu, Q. In vitro selection and identification of sweetpotato (Ipomoea batatas (L.) Lam.) plants tolerant to $\mathrm{NaCl}$. Plant Cell. Tissue Organ Cult. 2008, 96, 69-74. [CrossRef]

44. Xia, Z.; Wei, Y.; Sun, K.; Wu, J.; Wang, Y.; Wu, K. The maize AAA-type protein SKD1 confers enhanced salt and drought stress tolerance in transgenic tobacco by interacting with Lyst-interacting protein 5. PLoS ONE 2013, 8, e69787. [CrossRef]

45. Schmittgen, T.D.; Livak, K.J. Analyzing real-time PCR data by the comparative CT method. Nat. Protoc. 2008, 3, 1101-1108. [CrossRef]

46. O'Leary, B.; Park, J.; Plaxton, W.C. The remarkable diversity of plant PEPC (phosphoenolpyruvate carboxylase): Recent insights into the physiological functions and post-translational controls of non-photosynthetic PEPCs. Biochem. J. 2011, 436, 15-34. [CrossRef]

47. Shi, J.; Yi, K.; Liu, Y.; Xie, L.; Zhou, Z.; Chen, Y.; Hu, Z.; Zheng, T.; Liu, R.; Chen, Y.; et al. Phosphoenolpyruvate carboxylase in Arabidopsis leaves plays a crucial role in carbon and nitrogen metabolism. Plant Physiol. 2015, 167, 671-681. [CrossRef] [PubMed]

48. Kai, Y.; Matsumura, H.; Izui, K. Phosphoenolpyruvate carboxylase: Three-dimensional structure and molecular mechanisms. Arch. Biochem. Biophys. 2003, 414, 170-179. [CrossRef]

49. González-Segura, L.; Mújica-Jiménez, C.; Juárez-Díaz, J.A.; Güemez-Toro, R.; Martínez-Castilla, L.P.; Muñoz-Clares, R.A. Identification of the allosteric site for neutral amino acids in the maize $\mathrm{C}_{4}$-isozyme of phosphoenolpyruvate carboxylase: The critical role of Ser-100. J. Biol. Chem. 2018, 293, 9945-9957. [CrossRef] [PubMed]

50. Matsumura, H.; Xie, Y.; Shirakata, S.; Inoue, T.; Yoshinaga, T.; Ueno, Y.; Izui, K.; Kai, Y. Crystal structures of $\mathrm{C}_{4}$ form maize and quaternary complex of E. coli phosphoenolpyruvate carboxylases. Structure 2002, 10, 1721-1730. [CrossRef]

51. Kai, Y.; Matsumura, H.; Inoue, T.; Terada, K.; Nagara, Y.; Yoshinaga, T.; Kihara, A.; Tsumura, K.; Izui, K. Three-dimensional structure of phosphoenolpyruvate carboxylase: A proposed mechanism for allosteric inhibition. 1999, 96, 823-828. Proc. Natl. Acad. Sci. USA 1999, 96, 823-828. [CrossRef]

52. Winter, K.; Holtum, J.A. How closely do the $\delta 13 \mathrm{C}$ values of crassulacean acid metabolism plants reflect the proportion of $\mathrm{CO} 2$ fixed during fay and night? Plant Physiol. 2002, 129, 1843-1851. [CrossRef] 
53. Zhang, L.; Chen, F.; Zhang, G.Q.; Zhang, Y.Q.; Niu, S.; Xiong, J.-S.; Lin, Z.; Cheng, Z.M.; Liu, Z.J. Origin and mechanism of crassulacean acid metabolism in orchids as implied by comparative transcriptomics and genomics of the carbon fixation pathway. Plant J. 2016, 86, 175-185. [CrossRef] [PubMed]

54. Holtum, J.A.; Aranda, J.; Virgo, A.; Gehrig, H.H.; Winter, K. $\delta^{13} \mathrm{C}$ values and crassulacean acid metabolism in Clusia species from Panama. Trees 2004, 18, 658-668. [CrossRef]

55. Nunes-Nesi, A.; Araújo, W.L.; Fernie, A.R. Targeting mitochondrial metabolism and machinery as a means to enhance photosynthesis. Plant Physiol. 2010, 155, 101-107. [CrossRef]

56. Bräutigam, A.; Schlüter, U.; Eisenhut, M.; Gowik, U. On the evolutionary origin of CAM photosynthesis. Plant Physiol. 2017, 174, 473-477. [CrossRef]

57. Munns, R.; Termaat, A. Whole-plant responses to salinity. Funct. Plant Biol. 1986, 13, 143-160. [CrossRef]

58. Acosta-Motos, J.R.; Ortuño, M.F.; Bernal-Vicente, A.; Diaz-Vivancos, P.; Sanchez-Blanco, M.J.; Hernandez, J.A. Plant responses to salt stress: Adaptive mechanisms. Agronomy 2017, 7, 18. [CrossRef]

59. Patel, M.K.; Kumar, M.; Li, W.; Luo, Y.; Burritt, D.J.; Alkan, N.; Tran, L.-S.P. Enhancing salt tolerance of plants: From metabolic reprogramming to exogenous chemical treatments and molecular approaches. Cells 2020, 9, 2492. [CrossRef]

60. Boxall, S.F.; Kadu, N.; Dever, L.V.; Knerova, J.; Waller, J.L.; Gould, P.D.; Hartwell, J. Kalanchoë PPC1 is essential for crassulacean acid metabolism and the regulation of core circadian clock and guard cell signaling genes. Plant Cell 2020, 32, 1136-1160. [CrossRef] [PubMed]

61. Daloso, D.M.; Antunes, W.C.; Pinheiro, D.P.; Waquim, J.P.; AraÚJo, W.L.; Loureiro, M.E.; Fernie, A.R.; Williams, T. Tobacco guard cells fix CO 2 by both Rubisco and PEP case while sucrose acts as a substrate during light-induced stomatal opening. Plant Cell Environ. 2015, 38, 2353-2371. [CrossRef]

62. Li, L.; Sheen, J.J. Dynamic and diverse sugar signaling. Curr. Opin. Plant Biol. 2016, 33, 116-125. [CrossRef] [PubMed]

63. Wang, Y.-P.; Lei, Q.-Y. Metabolite sensing and signaling in cell metabolism. Signal Transduct. Target. Ther. 2018, 3, 1-9. [CrossRef] [PubMed]

64. Xiong, Y.; McCormack, M.P.; Li, L.; Hall, Q.; Xiang, C.; Sheen, J. Glucose-TOR signalling reprograms the transcriptome and activates meristems. Nat. Cell Biol. 2013, 496, 181-186. [CrossRef]

65. Sheen, J. Master regulators in plant glucose signaling networks. J. Plant Biol. 2014, 57, 67-79. [CrossRef]

66. Kandoi, D.; Mohanty, S.; Tripathy, B.C. Towards efficient photosynthesis: Overexpression of Zea mays phosphoenolpyruvate carboxylase in Arabidopsis thaliana. Photosynth. Res. 2016, 130, 47-72. [CrossRef]

67. Zhang, C.; Li, X.; He, Y.; Zhang, J.; Yan, T.; Liu, X. Physiological investigation of $\mathrm{C}_{4}$-phosphoenolpyruvate-carboxylase-introduced rice line shows that sucrose metabolism is involved in the improved drought tolerance. Plant Physiol. Biochem. 2017, 115, 328-342. [CrossRef] [PubMed]

68. Qian, B.; Li, X.; Liu, X.; Chen, P.; Ren, C.; Dai, C. Enhanced drought tolerance in transgenic rice over-expressing of maize $\mathrm{C}_{4}$ phosphoenolpyruvate carboxylase gene via $\mathrm{NO}$ and $\mathrm{Ca}^{2+}$. J. Plant Physiol. 2015, 175, 9-20. [CrossRef]

69. Ku, M.S.; Agarie, S.; Nomura, M.; Fukayama, H.; Tsuchida, H.; Ono, K.; Hirose, S.; Toki, S.; Miyao, M.; Matsuoka, M. High-level expression of maize phosphoenolpyruvate carboxylase in transgenic rice plants. Nat. Biotechnol. 1999, 17, 76-80. [CrossRef]

70. Ding, Z.-S.; Huang, S.-H.; Zhou, B.-Y.; Sun, X.-F.; Zhao, M. Over-expression of phosphoenolpyruvate carboxylase cDNA from C 4 millet (Seteria italica) increase rice photosynthesis and yield under upland condition but not in wetland fields. Plant Biotechnol. Rep. 2013, 7, 155-163. [CrossRef]

71. Lin, M.T.; Occhialini, A.; Andralojc, P.J.; Parry, M.A.J.; Hanson, M.R. A faster Rubisco with potential to increase photosynthesis in crops. Nat. Cell Biol. 2014, 513, 547-550. [CrossRef] [PubMed]

72. Kromdijk, J.; Głowacka, K.; Leonelli, L.; Gabilly, S.T.; Iwai, M.; Niyogi, K.K.; Long, S.P. Improving photosynthesis and crop productivity by accelerating recovery from photoprotection. Science 2016, 354, 857-861. [CrossRef]

73. Singha, D.L.; Tuteja, N.; Boro, D.; Hazarika, G.N.; Singh, S. Heterologous expression of PDH47 confers drought tolerance in indica rice. Plant Cell. Tissue Organ Cult. 2017, 130, 577-589. [CrossRef]

74. Wang, L.; Zhao, R.; Li, R.; Yu, W.; Yang, M.; Sheng, J.; Shen, L. Enhanced drought tolerance in tomato plants by overexpression of SIMAPK1. Plant Cell. Tissue Organ Cult. 2018, 133, 27-38. [CrossRef]

75. Roy, S.J.; Negrão, S.; Tester, M. Salt resistant crop plants. Curr. Opin. Biotechnol. 2014, 26, 115-124. [CrossRef] [PubMed]

76. Li, R.; Kang, C.; Song, X.; Yu, L.; Liu, D.; He, S.; Zhai, H.; Liu, Q. A ל-carotene desaturase gene, IbZDS, increases $\beta$-carotene and lutein contents and enhances salt tolerance in transgenic sweetpotato. Plant Sci. 2017, 262, 39-51. [CrossRef]

77. Liu, D.; He, S.; Song, X.; Zhai, H.; Liu, N.; Zhang, D.; Ren, Z.; Liu, Q. IbSIMT1, a novel salt-induced methyltransferase gene from Ipomoea batatas, is involved in salt tolerance. Plant Cell. Tissue Organ Cult. 2015, 120, 701-715. [CrossRef]

78. Ambavaram, M.M.; Basu, S.; Krishnan, A.; Ramegowda, V.; Batlang, U.; Rahman, L.; Baisakh, N.; Pereira, A. Coordinated regulation of photosynthesis in rice increases yield and tolerance to environmental stress. Nat. Commun. 2014, 5, 1-14. [CrossRef] [PubMed] 